\title{
A GPS network for tropospheric tomography in the framework of the Mediterranean hydrometeorological observatory Cévennes-Vivarais (southeastern France)
}

\author{
H. Brenot ${ }^{1,2,{ }^{*}, \text { A. Walpersdorf }}{ }^{1}$, M. Reverdy ${ }^{1,3,{ }^{* *}, \text { J. van Baelen }^{3}, \text { V. Ducrocq }}{ }^{2}$, C. Champollion ${ }^{4}$, F. Masson ${ }^{4, * * *}$, \\ E. Doerflinger ${ }^{4}$, P. Collard ${ }^{4}$, and P. Giroux ${ }^{1, * * * *}$ \\ ${ }^{1}$ ISTerre, CNRS, Université Joseph Fourier, UMR5275, Grenoble, France \\ ${ }^{2}$ CNRM-GAME, Météo-France \& CNRS, UMR3589, Toulouse, France \\ ${ }^{3}$ Laboratoire de Météorologie Physique, UMR6016 CNRS/UBP, Clermont-Ferrand, France \\ ${ }^{4}$ Geosciences Montpellier, Université de Montpellier II, Montpellier, France \\ *now at: Belgian Institute for Space Aeronomy, Brussels, Belgium \\ ** now at: Dynamic Meteorology Laboratory, Paris, France \\ **** now at: Institute of Earth Physics, Strasbourg, France \\ **** now at: Institute NÉEL, Grenoble, France
}

Correspondence to: H. Brenot (brenot@oma.be)

Received: 27 August 2013 - Published in Atmos. Meas. Tech. Discuss.: 6 November 2013

Revised: 13 January 2014 - Accepted: 14 January 2014 - Published: 19 February 2014

\begin{abstract}
The Mediterranean hydrometeorological observatory Cévennes-Vivarais (OHM-CV) coordinates hydrometeorological observations (radars, rain gauges, water level stations) on a regional scale in southeastern France. In the framework of OHM-CV, temporary GPS measurements have been carried out for 2 months in autumn 2002, when the heaviest rainfall are expected. These measurements increase the spatial density of the existing permanent GPS network, by adding three more receivers between the Mediterranean coast and the Cévennes-Vivarais range to monitor maritime source of water vapour flow feeding the precipitating systems over the Cévennes-Vivarais region. In addition, a local network of 18 receivers covered an area of 30 by $30 \mathrm{~km}$ within the field of view of the meteorological radar. These regional and local networks of permanent and temporary stations are used to monitor the precipitable water vapour (PWV) with high temporal resolution (15 min). Also, the dense local network provided data which have been inverted using tomographic techniques to obtain the 3-D field of tropospheric water vapour content. This study presents methodological tests for retrieving GPS tropospheric observations from dense networks, with the aim of assessing the uncertainties of GPS retrievals. Using optimal tropospheric GPS retrieval methods,
\end{abstract}

high resolution measurements of PWV on a local scale (a few kilometres) are discussed for rain events. Finally, the results of 3-D fields of water vapour densities from GPS tomography are analysed with respect to precipitation fields derived from a meteorological radar, showing a good correlation between precipitation and water vapour depletion areas.

\section{Introduction}

Water vapour is a very variable thermodynamic quantity in the atmosphere which influences atmospheric dynamics on very different temporal and spatial scales (from a climatic scale to a mesoscale). It controls, among other things, an important part of the energy and mass transfer in the atmosphere. Evaluating its temporal and spatial distribution is fundamental for improving meteorological forecasts, notably for precipitation forecasting.

Heavy rain and resulting flash floods in mid-altitude mountainous regions bordering the Mediterranean Sea are the centre of interest of the project "Observatoire Hydrométéorologique Méditerranéen Cévennes-Vivarais" (OHM-CV, 1, Delrieu et al., 2005). Figure 1 shows the 

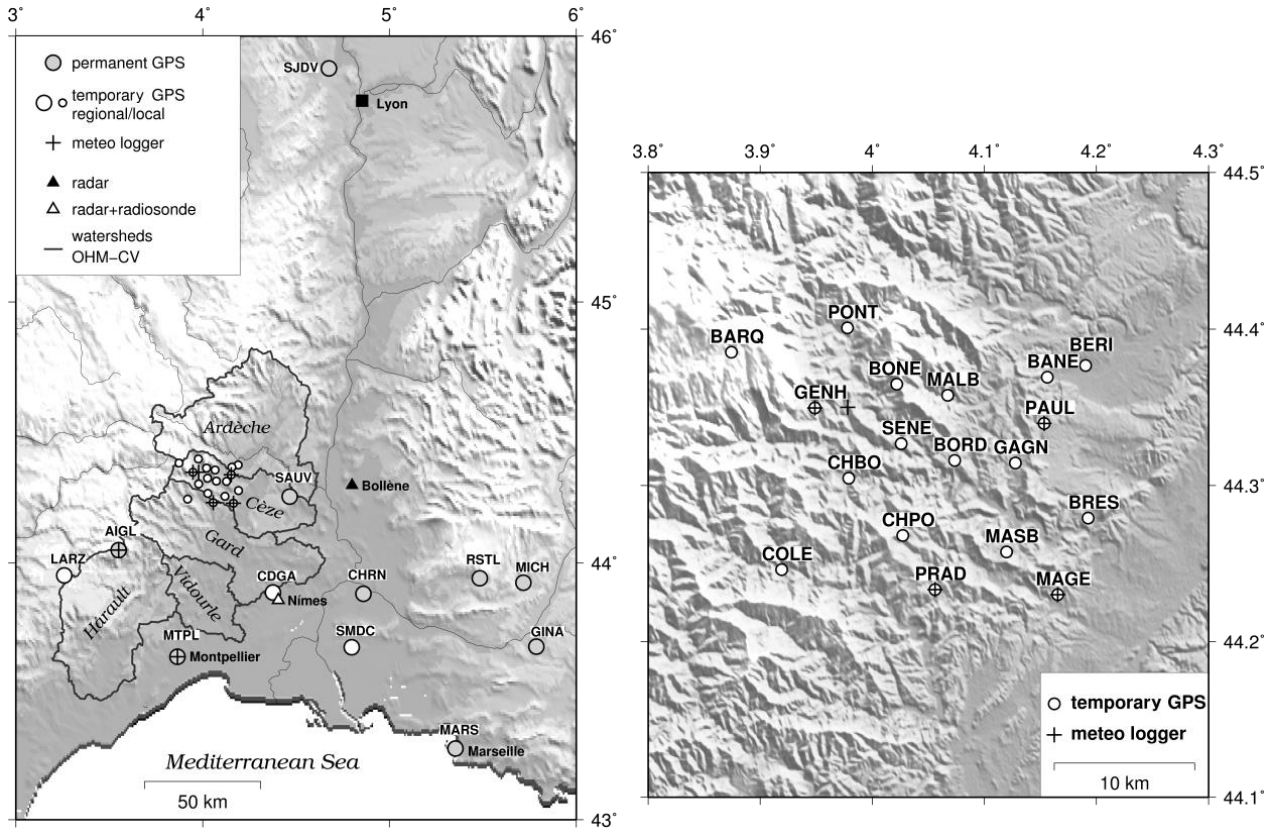

Fig. 1. Regional and local map of the GPS network (circles) and the meteorological data loggers (PTU stations, crosses) deployed for the campaign. Triangles show Météo France rain radars and radiosonde station. Grey contours indicate the water sheds surveyed by OHM-CV.

OHM-CV study zone, including the investigated watersheds. The Cévennes-Vivarais region is representative of the Mediterranean coastal mountainous regions. The intermittent rivers of the region undergo fast and devastating hydrological responses to extreme rain amounts showing one of the highest statistical frequency of flood events of the world (see Ceresetti, 2011).

Past studies have shown that atmospheric model performance in simulating heavy precipitation events is strongly dependent on the characteristics of the moist flow impinging on the region (Ducrocq et al., 2002; Bresson et al., 2012). However, moisture is recognised to be the least well analysed by present day operational assimilation systems, due to its strong intrinsic variability in space and time, and the limited availability of water vapour observations. The state of the art of operational techniques for water vapour retrievals (see Kämpfer, 2012) includes ground-based instruments (microwave radiometer, sun photometer, lidar, FTIR spectrometer, GNSS), in-situ methods (radiosonde and airborne instruments), and remote sensing (IR, visible and microwave sensors). The last technique can allow global coverage but no retrievals can be obtained during cloudy and rainy weather (for visible and IR sensors) or over lands (for microwave sensors). During severe weather conditions, it is recognised that the coverage by terrestrial measurements is insufficient to characterise correctly the three dimensional water vapour field at the mesoscale. For the Cévennes-Vivarais region, 2ma.g.l. humidity is described by Météo-France's weather surface network with one station every about $30 \mathrm{~km}$ and an hourly temporal resolution, but there is only one radiosonde station in the region (at Nîmes) providing vertical humidity profiles every $12 \mathrm{~h}$.

Within the OHM-CV framework, we completed the available measurements of humidity in a very significant way using GPS observations of tropospheric water vapour. GPS stations provide time series of precipitable water vapour (equivalent to integrated water vapour) above every site with a high temporal resolution (15 min in our case) and a precision comparable to radiosonde measurements or water vapour radiometers (within 1 to $2 \mathrm{~mm}$ of precipitable water) (Bevis et al., 1992, 1994; Rocken et al., 1995; Duan et al., 1996; Bock and Doerflinger, 2001; Van Baelen et al., 2005). Moreover, horizontal gradients of tropospheric water vapour can be estimated. They are very sensitive to local meteorological phenomena like the sea breeze and the diurnal cycle (Walpersdorf et al., 2001).

For this study and to obtain a good regional coverage (see Fig. 1), we have added 3 temporary stations to the permanent GPS stations network (8 stations) of the CévennesVivarais region. Such a regional network enables us to describe the incoming water vapour flow before it impinges on the Cévennes-Vivarais mountain range. There, it contributes to feeding the convective cells precipitating above the relief. In addition, to study the fine-scale variability of the water vapour field within the precipitating system regions, we set up a very dense network of 18 stations (covered an area of 30 by $30 \mathrm{~km}$ ) to retrieve the three dimensional water vapour field by tomographic inversion techniques. According to the 
position of the convective systems passing over the tomographic network (with a coverage of $900 \mathrm{~km}^{2}$ ), this network should be able to provide a detailed description of the water vapour field, such as the convective precipitation zone, the stratiform precipitation, dryer zone favouring evaporation or anomaly and blobs of water vapour.

In the following, a short description of the present use of GPS observations for meteorology (Sect. 2) is provided, followed by an overview of the field measurement campaign (Sect. 3). In Sect. 4, several GPS tropospheric parameter estimation strategies are evaluated for combining a dense, local network and a more widely spread regional network with a total of 44 sites. This allows us to evaluate the uncertainties associated with the different tropospheric GPS retrieval methods and, thus, products. The major products of GPS meteorological solutions are the time series and 2-D maps of the PWV (Precipitable Water Vapour) distribution as well as the 3-D water vapour fields through tomographic inversion. These are the objects of Sects. 5 and 6, respectively. Furthermore, in these sections, we will examine the possible relationship between the water vapour field evolution and the rainfall estimation provided by a near-by precipitation radar, as well as the role of water vapour in the convective system's life cycle. In particular, we will focus on the rain event on the 21 October 2002, first to illustrate our methodological work, and then as an example to support comparisons between the GPS retrieved water vapour fields and radar retrieved precipitation observations. In the final Sect. 7, we present conclusions and perspectives for high resolution water vapour retrieval by GPS tomography.

\section{State-of-the-art: GPS met applications}

The sensitivity of GPS measurements to tropospheric water vapour designates GPS as an adequate technique for remote sensing of atmospheric humidity (Bevis et al., 1992). Methodological studies of meteorological GPS applications have been carried out over the last two decades (e.g. Bevis et al., 1992; Businger et al., 1996; Tregoning et al., 1998; Bock and Doerflinger, 2001; Walpersdorf et al., 2007) and enable us now to infer precipitable water vapour (PWV in $\mathrm{mm}$, equivalent to Integrated Water Vapour content, IWV in $\mathrm{kg} \mathrm{m}^{-2}$ ) from GPS observations with the same precision as conventional meteorological measurements, such as radiosondes and microwave water vapour radiometers (WVR), to about 1-2 mm PWV. GPS atmospheric measurements have been validated by comparisons with independent measurements and numerical weather prediction models (Yang et al., 1999; Vedel et al., 2001; Behrend et al., 2002; Pacione et al., 2002; Haase et al., 2003; Van Baelen et al., 2005; Bock et al., 2007; Schneider et al., 2010). Raw GPS tropospheric delay (zenith total delay: ZTD) or the inferred PWV estimation have several advantages over traditional meteorological measurements of water vapour: it can be done at low cost (either by using already existing GPS stations or by installing new GPS stations which are less expensive than other instruments), it performs in all-weather conditions and the method is intrinsically stable (Wang et al., 2007). Effectively, GPS ZTD measurements are based on the exploitation of propagation delays excluding any instrumental drifts (contrary to other sensors like spectrometers onboard polar orbiting satellites). Nevertheless, modifications of the analysis strategy or the change of instruments (receiver and/or antenna) can induce instantaneous offsets in the coordinate time series. However, the effect on the tropospheric parameter estimates is limited as an error in the vertical positioning is downweighted by a factor of about 3 for the tropospheric parameter estimation (Santerre et al., 1991; Niell, 1996). In fact, the vertical position error (mainly induced by the amplitude of the major ocean loading component that is related to the semi-diurnal lunar tides, so-called component M2) is about $20 \mathrm{~mm}$, and in comparison the ZTD error is about $6.5 \mathrm{~mm}$ (Walpersdorf et al., 2007). The GPS performance has been tested in the continuously growing GPS permanent networks (for navigation, reference frame and seismo-tectonic monitoring) where it has shown good results. Presently, applications in meteorological analysis and weather forecast are widely spread in European, US and Japanese weather services (Gendt et al., 2004; Gutman et al., 2004; Nakamura et al., 2004; Guerova et al., 2006; Smith et al., 2007; Poli et al., 2007; Macpherson et al., 2008; Yan et al., 2009; Benjamin et al., 2010).

The main applications of tropospheric water vapour estimates from ground-based GPS data are:

- The analysis of meteorological events from postprocessed GPS data (e.g. Bock et al., 2004; Walpersdorf et al., 2004; Brenot et al., 2006; Van Baelen et al., 2011; Labbouz et al., 2013) and process-oriented studies (such as understanding the fundamentals of deep tropical convection, see Adams et al., 2013).

- Climatological applications by post-processing long time series of data with the same coherent analysis strategy (e.g. Wang et al., 2007; Sguerso et al., 2013).

- The assimilation of ZTD in operational numerical weather prediction (NWP) systems (e.g. Gutman et al., 2004; Bennitt and Jupp, 2012) and the use of GPS observations by forecasters (such as an indicator of deep convection, see Brenot et al., 2013). The operational applications require near-real time analysis of the data, done by downloading hourly data followed by a time optimised processing to provide tropospheric parameters with a latency of $1 \mathrm{~h}$ (EC COST 716/MAGIC/TOUGH recommendations (Elgered et al., 2001; Van der Marel, 2004; Guerova et al., 2006) and the EUMETNET GPS Water Vapour project (EGVAP; Haan et al., 2006)). 




Fig. 2. Schematic representation of the GPS tropospheric observables Zenith Total Delay (ZTD) and horizontal gradients (EW and NS components, here EW component $G_{\mathrm{EW}}$ ). They are inferred from all simultaneously available GPS observations via elevation $(\varepsilon)$ dependent isotropic mapping functions $m_{\text {iso }}(\varepsilon)$ and via azimuthal $(\alpha)$ and elevation $(\varepsilon)$ dependent anisotropic mapping functions $m_{\text {ani }}(\varepsilon, \alpha)$

- Tomographic inversion of line-of-sight tropospheric delays to establish 3-D water vapour fields. This tomographic technique has the potential to provide atmospheric water vapour fields with a horizontal resolution of several kilometres, a vertical resolution of $500 \mathrm{~m}$ in the lower troposphere and $2 \mathrm{~km}$ in the upper troposphere, and a time resolution of $15 \mathrm{~min}$, but it requires a dense homogeneously distributed network of GPS stations. First comparisons of tomographic observations with other measurement techniques (WVR, radiosondes) and with meteorological models give encouraging results (Elgered et al., 1991; Gradinarski, 2002; Gradinarski and Jarlemark, 2004; Champollion et al., 2005; Bastin et al., 2005; Troller et al., 2006; Perler et al., 2011; Van Baelen et al., 2011). However, to obtain the indicated resolution, the tomographic inversion requires data from a dense network of GPS stations (5-25 km spacing), possibly with stations at different altitudes. This calls therefore for dedicated networks. The permanent GPS networks currently available in France provide about one station each $50 \mathrm{~km}$.

Two "direct" GPS tropospheric measurements are exploited nowadays: zenith total delay (ZTD) and horizontal gradients of refractivity (GRAD) (Fig. 2). They are related to the air refractivity along the signal travel path and can be converted to values of PWV using measurements or model data for surface pressure and temperature (Bevis et al., 1992). To do so, keep in mind that ZTD can be split into a hydrostatic (zenith hydrostatic delay: ZHD) and a wet component (zenith wet delay: ZWD) (Saastamoinen, 1972; Davis et al., 1985; Elgered et al., 1991):

$\mathrm{ZTD}=\mathrm{ZHD}+\mathrm{ZWD}$.
ZHD can be inferred from surface pressure $P_{\mathrm{S}}$ (e.g. Davis et al., 1985)

$\mathrm{ZHD}=(2.2768 \pm 0.0015) \cdot 10^{-5} P_{\mathrm{S}} / f(\theta, H)$

with $f(\theta, H)=1-0.00266 \cos 2 \theta-0.000279 H$, being a function of latitude $\theta$ and altitude in $\mathrm{km}$ above the ellipsoid $H$ (see Vedel et al., 2001). This enables us to extract the value of ZWD by subtracting ZHD inferred from surface pressure from GPS measured ZTD:

$\mathrm{ZWD}=\mathrm{ZTD}_{\mathrm{GPS}}-\mathrm{ZHD} \mathrm{PS}$.

According to Bevis et al. (1992), this ZWD can be approximated by

$\mathrm{ZWD} \approx(0.382 \pm 0.004) R_{\mathrm{V}} \int \rho_{\mathrm{V}} / T \mathrm{~d} z$

with $R_{\mathrm{V}}$ the gas constant for water vapour, $\rho_{\mathrm{V}}$ the water vapour density and $T$ the temperature along a vertical profile. Its expression is close to the integrated water vapour (IWV expressed in $\left.\mathrm{kg} \mathrm{m}^{-2}\right)$. Considering a standard mean liquid water density for the vertical column $\left(\sim 1000 \mathrm{~kg} \mathrm{~m}^{-3}\right)$, this study assumes that IWV is equivalent to the precipitable water vapour (PWV expressed in $\mathrm{mm}$ ):

$\mathrm{IWV}=\int \rho_{\mathrm{V}} \mathrm{d} z \sim \mathrm{PWV}$.

Therefore, PWV is almost proportional to ZWD (Bevis et al., 1992):

$\mathrm{PWV}=\kappa \cdot \mathrm{ZWD}$

with

$\kappa_{\text {Bevis }}=10^{8} /\left[R_{\mathrm{V}}\left(k_{3} / T_{\mathrm{M}}+k_{2}^{\prime}\right)\right]$

with $\quad R_{\mathrm{V}}=(461.525 \pm 0.013) \mathrm{J} /(\mathrm{kmol} \mathrm{K}) \quad$ the specific molar gas constant for water vapour, $k_{3}=$ (373 $900 \pm 1200) \mathrm{K}^{2} \mathrm{~Pa}^{-1}$ and $k_{2}^{\prime}=(0.221 \pm 0.023) \mathrm{K} \mathrm{Pa}^{-1}$ being refractivity coefficients (Bevis et al., 1994) and $T_{\mathrm{M}}$ being the mean temperature in the atmospheric column according to Askne and Nordius (1987), that can be approximated using a measurement of the surface temperature $T_{\mathrm{S}}$ in $\mathrm{K}$ :

$T_{\mathrm{M}} \approx 70.2+0.72 T_{\mathrm{S}}$.

This formulation of $\kappa_{\text {Bevis }}$ by Bevis et al. (1994) considers a global climatology (8718 radio soundings in the US covering a latitude range of $27^{\circ} \mathrm{N}$ to $65^{\circ} \mathrm{N}$ ). The precision of $\kappa$ is evaluated to $2 \%$. In this study, we use the formulation $\kappa_{\mathrm{E} \& \mathrm{D}}$ of Emardson and Derks (1999) specific to the Mediterranean region:

$$
\begin{aligned}
\kappa_{\mathrm{E} \& \mathrm{D}} & =10^{3} /\left[6.324-0.0177\left(T_{\mathrm{S}}-289.76\right)\right. \\
& \left.+0.000075\left(T_{\mathrm{S}}-289.76\right)^{2}\right] .
\end{aligned}
$$


For a surface temperature of $298 \mathrm{~K}$ this yields an average value for the dimensionless $\kappa_{\mathrm{E} \& \mathrm{D}}$ of about 0.165 and a relation between PWV and ZWD of

$1 \mathrm{~mm} \mathrm{PWV} \Leftrightarrow 6.18 \mathrm{~mm}$ ZWD.

The direct ZTD measurement is the preferred quantity for assimilation and climatology, to avoid adding GPS external information related to the reduction of ZTD to ZWD and to the conversion of ZWD to PWV (Brenot et al., 2006). However, GPS PWV above each station and its horizontal gradients are useful for meteorological analyses and tomographic inversion.

\section{OHM-CV tomographic measurement campaign}

The temporary GPS network implemented in OHM-CV has been conceived to provide tropospheric water vapour observations for the analysis of precipitation events, and to perform tropospheric tomography. The tomographic inversion of GPS data requires a fairly dense network of stations (5$25 \mathrm{~km}$ inter-station spacing) so that the different rays from satellites to the different GPS receivers can interweave and allow the restitution of the 3-D distribution of water vapour fields (resolution of few kilometres in horizontal and few $100 \mathrm{~m}$ in vertical). Our study is part of a limited number of tomographic applications that have been achieved so far, such as the experiments undertaken by IEEC (Spain) (Flores et al., 2000) in the framework of the WAVEFRONT program, by ETH Zurich in Switzerland (Troller et al., 2006; Perler et al., 2011), as well as by UCAR (USA) (Braun et al., 2001). A first experiment of GPS tomography was conducted in France in 2001 in the framework of the ESCOMPTE campaign (Bock et al., 2004; Walpersdorf et al., 2004) which took place in the Marseille region. For that study, the tomographic routine (LOFFTK) was employed for the GPS inversion (Champollion et al., 2005; Bastin et al., 2005). Based on this experience, a new software, called TSAAR (Tomography Software for wAter vApour Retrieval) has been developed by the authors. A full series of tests and validations are presented in Reverdy (2008) whereas its application to the COPS campaign is described in Van Baelen et al. (2011). TSAAR will be used for the GPS tomography in this study.

The OHM-CV GPS measurement campaign aims at covering efficiently the region between the Mediterranean and the OHM-CV water sheds. A complete spatial coverage of GPS tropospheric observations requires relatively dense networks. Indeed, the tropospheric ZTD and horizontal gradients calculations of a GPS station are obtained by averaging signals from all GPS satellites visible simultaneously under different elevation angles. In our measurements, 6 to 10 satellites are visible simultaneously, probing an atmospheric volume in a cone between the GPS station and the tropopause, limited by the cut-off angle. With a cut-off angle of $5^{\circ}$, this tropospheric cone has a radius of about $110 \mathrm{~km}$ at the height of
Table 1. Positions of temporary GPS stations in WGS84.

\begin{tabular}{lrrr}
\hline SITE & $\begin{array}{r}\text { Latitude } \\
{\left[{ }^{\circ} \mathrm{N}\right]}\end{array}$ & $\begin{array}{r}\text { Longitude } \\
{\left[{ }^{\circ} \mathrm{E}\right]}\end{array}$ & $\begin{array}{r}\text { Altitude } \\
{[\mathrm{m}]}\end{array}$ \\
\hline BERI & 44.377 & 4.190 & 194.71 \\
GAGN & 44.314 & 4.128 & 234.97 \\
MAGE & 44.230 & 4.166 & 260.69 \\
BRES & 44.279 & 4.193 & 273.48 \\
PAUL & 44.340 & 4.153 & 316.85 \\
CHBO & 44.305 & 3.979 & 341.93 \\
BANE & 44.369 & 4.156 & 356.50 \\
COLE & 44.246 & 3.919 & 358.04 \\
MASB & 44.257 & 4.120 & 359.64 \\
PRAD & 44.233 & 4.056 & 448.53 \\
BORD & 44.316 & 4.073 & 456.54 \\
MALB & 44.358 & 4.067 & 489.24 \\
SENE & 44.327 & 4.026 & 505.38 \\
GENH & 44.350 & 3.949 & 561.63 \\
PONT & 44.401 & 3.978 & 563.85 \\
CHPO & 44.268 & 4.027 & 640.92 \\
BONE & 44.365 & 4.022 & 847.90 \\
BARQ & 44.385 & 3.874 & 1470.97 \\
SMDC & 43.674 & 4.799 & 65.09 \\
CDGA & 43.886 & 4.376 & 231.95 \\
LARZ & 43.952 & 3.259 & 806.92 \\
\hline
\end{tabular}

the tropopause (about $10 \mathrm{~km}$ at mid-latitudes). However, due to the exponential decrease of air density, most of the tropospheric variability is seen in the lower part of the troposphere. The water vapour scale height is about $2-3 \mathrm{~km}$. At these altitudes, the lines of sight reach distances of $16-24 \mathrm{~km}$ from the site. That means that stations spaced by about $20 \mathrm{~km}$ are needed to continuously sample the low tropospheric water vapour field.

From 15 September to 21 November 2002, 21 GPS receivers were deployed in the region Cévennes-Vivarais and south to the Mediterranean coast (Fig. 1, Table 1). 18 receivers were used to set-up the dense tomographic network of about $900 \mathrm{~km}^{2}$ with baseline lengths of 3 to $8 \mathrm{~km}$. The range of receiver altitudes covered by this local network is from $195 \mathrm{~m}$ to $1471 \mathrm{~m}$. Three receivers completed the permanent regional network of about $40000 \mathrm{~km}^{2}$ (from CévennesVivarais range to the Mediterranean coast) to obtain a station spacing of about $50 \mathrm{~km}$. The GPS receivers were Ashtech Z12 receivers with choke-ring antennas. The cut-off angle used for the measurements was $5^{\circ}$. The GPS network was completed by 5 meteorological data loggers (mostly Vaisala PTU 200, see Fig. 1 for location) recording surface pressure, temperature and relative humidity at some stations of the local GPS network. Additional measurements available for the GPS campaign are surface pressure and temperature observations from the Météo-France network, and 00:00 and 12:00 UTC radiosoundings from the closest Météo-France radiosonde station at Nîmes (see Fig. 1). This station is situated outside of the dense tomographic GPS network and 
therefore cannot be used to validate or constrain our tomographic inversion, but it is located close to one regional temporary GPS site (CDGA, at $5 \mathrm{~km}$ distance). Therefore, we can use the radiosonde data for methodology validation by comparing with the CDGA tropospheric GPS observations (see Sect. 5.2). Finally, the Météo-France weather radar in Bollène in the Rhône valley (see Fig. 1) provides 2-D fields of reflectivity with good temporal and spatial coverage (Delrieu et al., 2005) over the entire domain of our tomographic GPS network. This enables us to correlate GPS inferred water vapour observations with radar reflectivity fields (Reverdy, 2008) and, thus, precipitation systems.

\section{GPS data analysis and sensitivity tests}

The GPS data analysis has been performed with MIT's GAMIT/GLOBK package (GAMIT version 10.3, Herring et al., 2006). The temporary network (21 stations) has been completed with 11 permanent stations from the French RENAG network (REseau NAtional GPS permanent, http://webrenag.unice.fr), 11 of the EUREF and the IGS network, and with 1 station from ROA, Spain. The furthest reference stations are situated at $2000 \mathrm{~km}$ distance from the local network, which will enable us to de-correlate vertical positioning from tropospheric parameter estimation (Tregoning et al., 1998). IGS final orbits have been held fixed in the analysis, and corresponding earth orientation parameters have been employed. The mapping function used for the tropospheric parameter estimation is Niell's (NMF, 1996). Several other mapping functions are commonly used nowadays (IMF, Niell, 2000; GMF, Boehm et al., 2006a; VMF1, Boehm et al., 2006b) and their performance is comparable (Boehm et al., 2006a). The differences in the tropospheric parameter estimation concern in particular the hydrostatic component of the tropospheric delay, indicating that the choice of the NMF is not critical for modelling the short term variability of tropospheric delay related to water vapour fluctuations in a regional network.

The tropospheric parameters have been established using a two step analysis: the first one calculates the precise positions in our network, and the second one determines tropospheric parameters with high temporal resolution using the precise coordinates of our campaign sites, considering $12 \mathrm{~h}$ of data for each session of calculations and applying a sliding window strategy (see Brenot et al., 2006 for more details). For each of the stations, ZTD were obtained every $15 \mathrm{~min}$ and one couple of horizontal tropospheric gradients (NS and EW component) every $30 \mathrm{~min}$. For this second analysis step, we established a series of sensitivity tests that are presented in the following subsections.

\subsection{Network geometry}

The calculation time increases with the square of the number of stations included in the GAMIT analysis. At the time of the calculations, estimating 49 ZTD and $25 \times 2$ gradients (GRAD) for each station of the 44 station network in each $12 \mathrm{~h}$ session was at the limit of our processing capacities. Therefore, we decided to build sub-networks in this step of the analysis, optimising the calculation time. This is a common strategy to analyse in an operational way large networks of permanent stations. While the influence of network splitting on station coordinates has been evaluated already (e.g. Ineichen et al., 1999, who evaluated an rms of 1 to $4 \mathrm{~mm}$ for station coordinates estimated in different sub-networks), an effect on tropospheric parameter estimation was recognised but has not yet been quantified in detail. For example, Haase et al. (2003) used three sub-networks for tropospheric parameter estimations in a regional network of 51 stations, and indicated that $7 \mathrm{~mm}$ was a good estimate for the random error of GPS ZTD.

For our network of 44 stations, we calculated one reference solution including all stations, covering the test interval from 20-22 October 2002. Then we tested different sub-networks sizes and geometries and could infer a value for the uncertainties of tropospheric parameters with respect to the various sub-network choices. A graphical representation of the variability of ZTD and GRAD between different tests and the reference solution is given in Fig. 3 (note that GAMIT software provides horizontal gradient components normalised to an elevation of $10^{\circ}$ ). The details about the 36 different network choices and the numerical results can be found in Appendix.

Our tests quantify the ZTD variability, and therefore potential miss-estimation to a bias of $0-1.5 \mathrm{~mm}$ and a $2-3.5 \mathrm{~mm}$ standard deviation (std). Variability for EW gradients is characterised by a $0.5-3.5 \mathrm{~mm}$ bias and a $10-20 \mathrm{~mm}$ std, and for NS gradients by a $2-7 \mathrm{~mm}$ bias and a $15-30 \mathrm{~mm}$ std. This shows that estimations of ZTD are rather stable, while for GRAD the number of stations and the geographical distribution are critical. Note that ZTD and GRAD observations are the results of a mean estimation which use double differences of data records from several stations in the direction of several satellites (see Brenot and Warnant, 2008). Increased ZTD and gradient biases are mainly due to large distances between the GPS sites in addition to a small number of stations (less than 20).

The choice of the geometry of the network has also shown some results about the uncertainty of the two components (NS, EW) of horizontal gradients. In fact, clusters of local stations increase the dispersion of the NS gradients with respect to sub-networks with regular sub-sampling of the whole network. Dispersion of the NS component is generally higher than for the EW component, probably due to the $55^{\circ}$ inclination of the GPS satellite orbits creating a gap in satellite coverage to the north in the Northern Hemisphere. 
a)
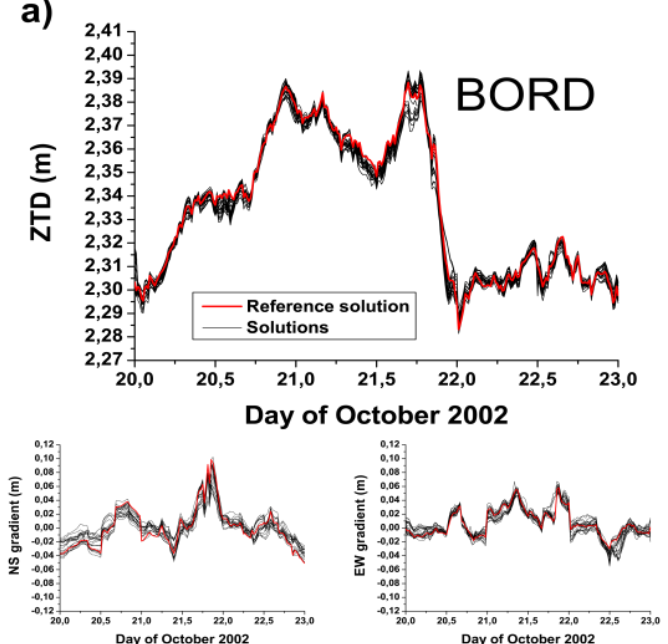

c)

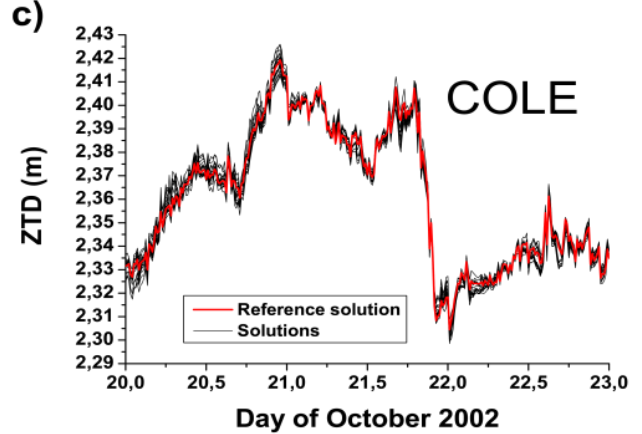

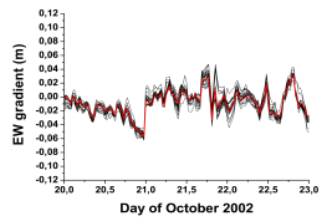

e)
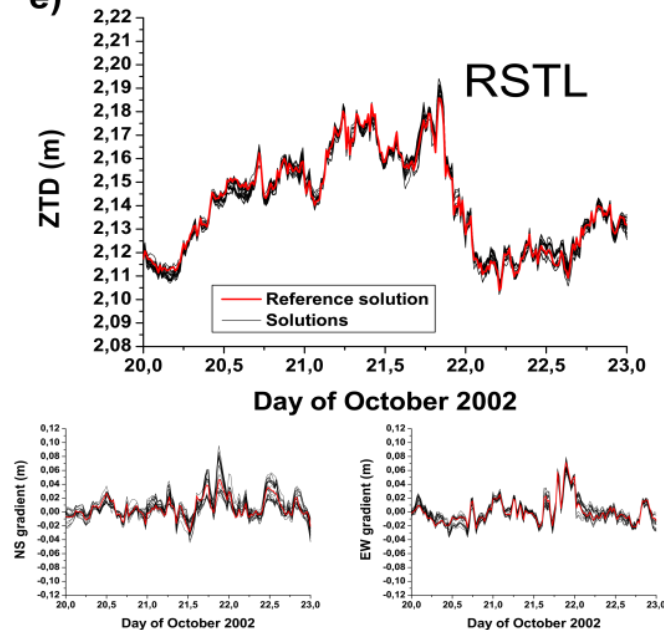

b)
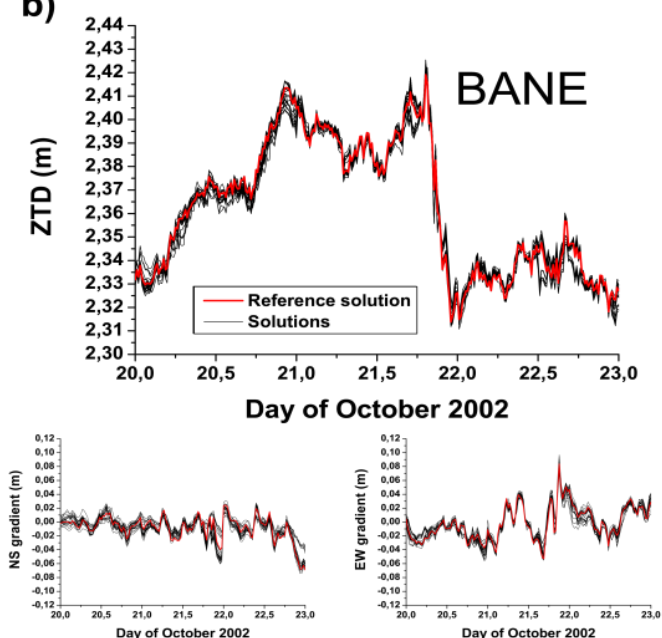

d)
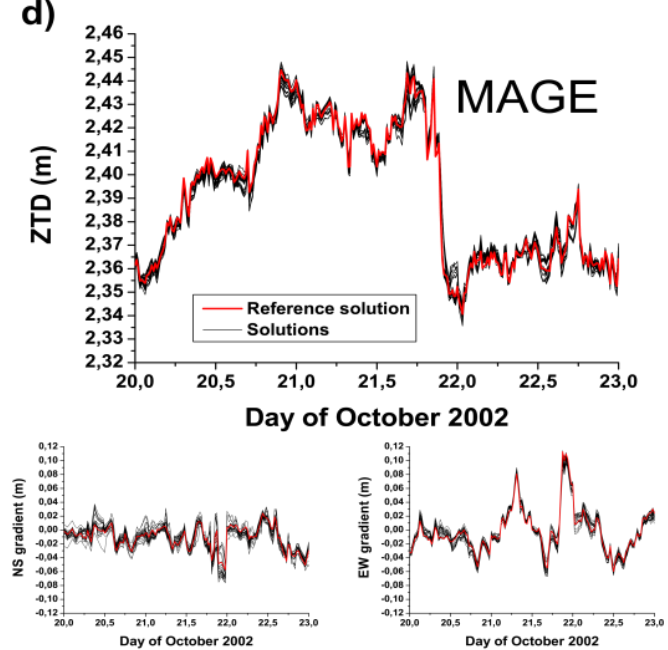

f)
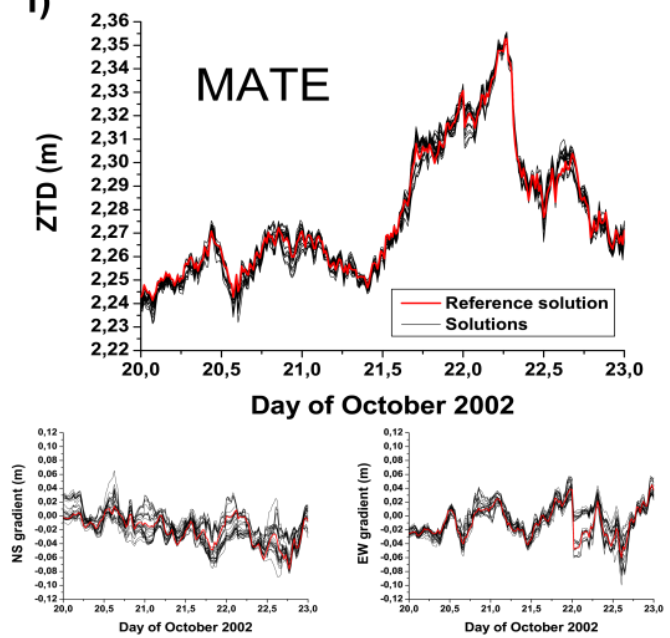

Fig. 3. ZTDs and horizontal gradients (NS and EW components) from different geometric network configurations for 6 stations: (a-d) 4 local stations (BORD, BANE, COLE and MAGE), (e) RSTL (Rustrel) a permanent station from the French RENAG network, (f) MATE (Matera, Italy) a EUREF reference stations. Thirty-six solutions are shown over the interval covering 20-22 October 2002 (day of year 293-295). All solutions apply standard constraints on tropospheric parameter variability and are established in a free reference frame. 
Exceptionally high dispersion of the EW component was observed for stations at the edge of the network with a low number of stations in the network (example of MATE station Fig. 3f). GRAD variations are lower for stations in the centre of the network and for networks with more than 4-5 local stations. To increase the precision of GRADs, we can increase the number of stations. A good compromise for an efficient operational analysis is to use sub-networks of 24 stations including 10 widely spread reference stations and respecting regular sub-sampling of the total network. In comparison to the reference solution of 44 stations, the dispersion of these operational calculations is limited to $3 \mathrm{~mm}$ for ZTD and $15 \mathrm{~mm}$ for GRADs.

\subsection{Choice of reference frame}

Two choices of reference frame for the tropospheric parameter estimation are possible and commonly used: (a) the ITRF reference frame, established by including IGS stations with coordinates and velocities well-determined; e.g. in the ITRF2000 solution (Altamimi et al., 2002), and imposing high constraints on these positions $(1-2 \mathrm{~mm})$ in the GAMIT solution (e.g. Haase et al., 2003); (b) a relaxed reference frame constraining some reference sites to their coordinates from the unconstrained global solution (established by GLOBK, in our case). Note that this relaxed reference frame has been used in Sect. 4.1. We estimated ZTD and horizontal gradients with both strategies. In both cases, we apply loose constraints on all the regional and local sites we are interested in for their tropospheric observations.

Figure 4 shows the time series of ZTDs and horizontal gradients for the same 6 stations as in Fig. 3, with the MATE station being one of the stations used for the ITRF reference frame establishment (with its coordinates constrained to the ITRF2000 solution), while the other five stations are only loosely constrained. The comparison of ZTDs evaluated in ITRF or a free reference frame shows for most of the permanent and temporary stations a bias of about $4 \mathrm{~mm}$ between the solutions, the $\mathrm{ZTD}_{\mathrm{ITRF}}$ being higher. Gradients vary by 1 to $3 \mathrm{~mm}$ for the local temporary sites and the closeby permanent RSTL station, while at MATE the differences reach $8 \mathrm{~mm}$. The differences for the 6 test sites are resumed in Table 2. These differences in tropospheric parameter evaluations are due to constraining the coordinates to the ITRF solution, but also to the location at the limit of the network. In particular, our results highlight that the choice of the reference frame is more critical for stations at the edge of the network.

We tried to identify a more appropriate reference frame by comparison of ZTD evaluations with radiosonde (RS) data as independent measurements. The data used for this comparison are 21 days of radio soundings twice a day (00:00 and 12:00 UTC) at the Nîmes meteorological station (localisation on Fig. 1) and GPS data from the CDGA site at $5 \mathrm{~km}$ from the radiosonde and at $\sim 200 \mathrm{~m}$ higher altitude. The RS observations of pressure $(P)$, temperature $(T)$ and virtual temperature $\left(T_{\mathrm{V}}\right)$ have been converted into ZTD using the following relation:

$$
\begin{aligned}
\mathrm{ZTD}_{\mathrm{RS}} & =10^{-6} \int_{0}^{z_{0}}\left(k_{1} \frac{P}{T_{\mathrm{v}}}+k_{2} \frac{e}{T}+k_{3} \frac{e}{T^{2}}\right) \mathrm{d} z \\
& +\Delta \mathrm{ZTD}_{\text {top }}-\Delta \mathrm{ZTD}_{\text {alt }} .
\end{aligned}
$$

We consider $k_{1}=\chi \cdot(1+\beta \cdot P / T)$ with $\chi=0.7755 \mathrm{~K} \mathrm{~Pa}^{-1}$ and $\beta=1.3 \times 10^{-7} \mathrm{~K} \mathrm{~Pa}^{-1}$ (Brenot et al., 2006). Constant values of $k_{2}=(0.704 \pm 0.022) \mathrm{K} \mathrm{Pa}^{-1}$ and $k_{3}=$ $(373900 \pm 1200) \mathrm{K}^{2} \mathrm{~Pa}^{-1}$ have been used (Bevis et al., 1994). The contribution of the top of the atmosphere at the altitude $z_{\text {top }}$ (last level of the RS measurement) to the tropospheric delay has been calculated with the formulation of Saastamoinen (1972). The mean value for $\Delta \mathrm{ZTD}_{\text {top }}$ is $74.7 \mathrm{~cm}$ with a standard deviation of $5.4 \mathrm{~cm}$, neglecting any contribution from water vapour in this part of the troposphere. $\Delta \mathrm{ZTD}_{\text {alt }}$ corresponds to an altitude correction considering the difference of ZHD between RS and GPS sites (difference of altitude and pressure, see Eq. 2). The different parameters entering in the $\mathrm{ZTD}_{\mathrm{RS}}$ calculation have typical uncertainties of $2 \mathrm{hPa}$ for pressure and $0.2 \mathrm{~K}$ for temperature at each level of the RS measurements, and of $1 \mathrm{~m}$ for the altitude of the measurements at the ground level, increasing progressively to $200 \mathrm{~m}$ for the last level. The refractivity constants have uncertainties related to $P$ and $T$ for $k_{1}$ and those given by Bevis et al. (1994) for $k_{2}$ and $k_{3}$. To estimate the uncertainty propagated on $\mathrm{ZTD}_{\mathrm{RS}}$ we vary each of the different parameters by their supposed uncertainty and compare the result with the reference solution without uncertainties. Accumulating the results over the 21 days of the experiment, we infer a mean bias of about $10 \mathrm{~mm}$ with a standard deviation of $4 \mathrm{~mm}$, representing the total uncertainty of the ZTD evaluation from RS data (Table 3 ).

The comparison between "free" and ITRF ZTD solutions and ZTD evaluated from RS data shows a slightly better correlation for the "free" solution with RS data than for the ITRF solution (Fig. 5, Table 4). The "free" solution has a bias of $2 \mathrm{~mm}$ and a standard deviation of $14 \mathrm{~mm}$ with respect to RS data. The bias of $2 \mathrm{~mm}$ ZTD corresponds to $0.4 \mathrm{~mm}$ PWV and is inside the chosen error limit (1 mm PW). Our result is coherent for example with studies of Haase et al. (2001, 2003), comparing $3 \mathrm{yr}$ of ZTD from operational near-real time analysis with radiosonde measurements at 14 stations and evaluating a bias of $5 \mathrm{~mm}$ with a std of $10 \mathrm{~mm}$. We verify whether the fact of removing constraints on station coordinates introduces an anti-correlation between the estimates of vertical positions and ZTD. Figure 5 shows the vertical position time series of the CDGA station from the unconstrained ("free") and the constrained solution (ITRF). These positions have been estimated simultaneously with the tropospheric parameters during 61 days in six 12-h sessions per day. A quasi-constant bias of vertical position of about $39 \mathrm{~cm}$ has 
a)


c)
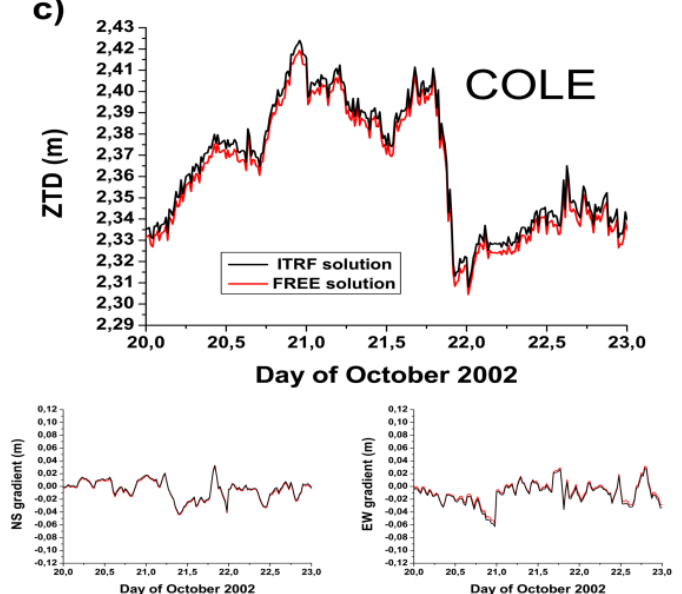

e)


b)
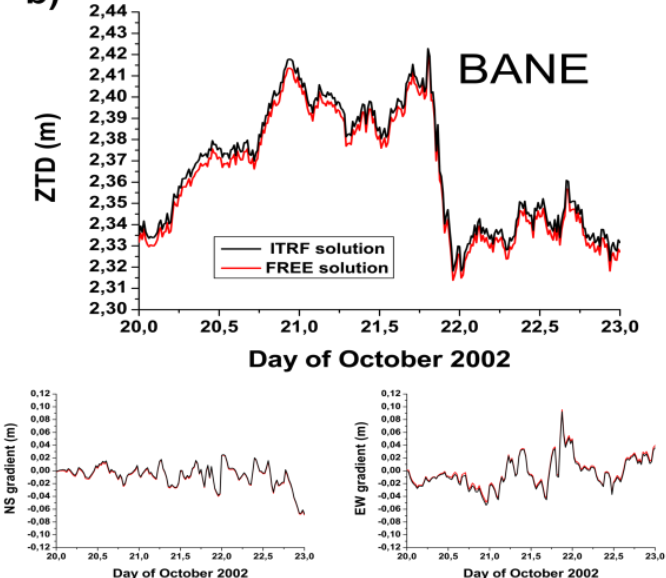

d)
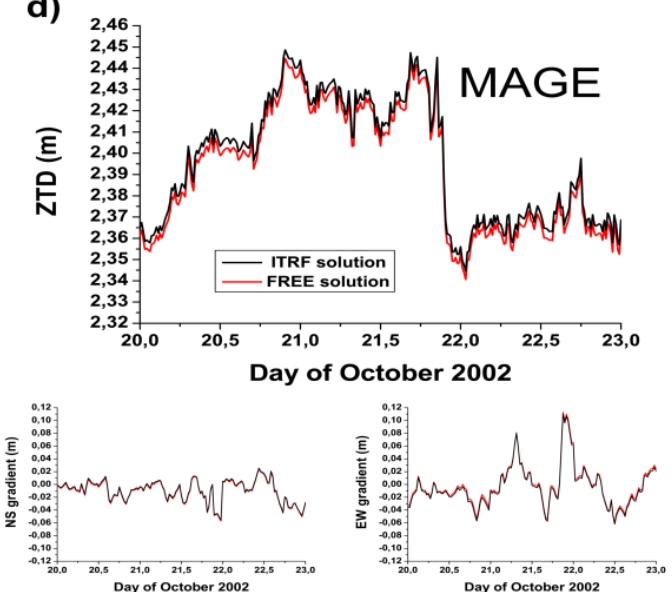

f)
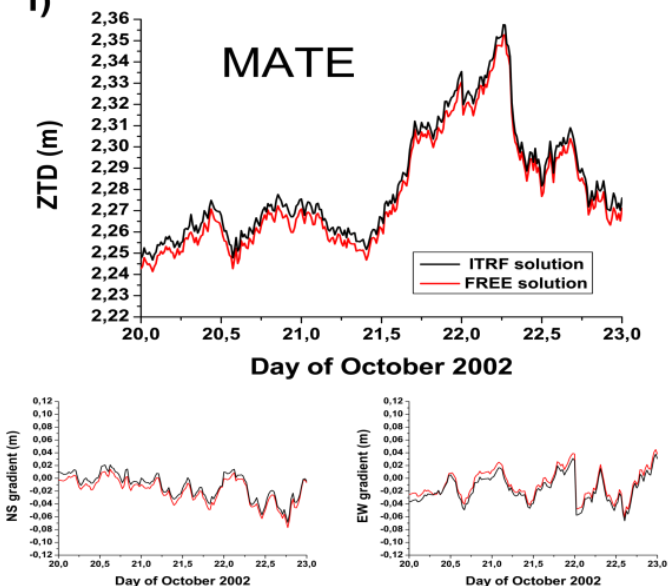

Fig. 4. Comparison of ZTDs and GRADs (NS and EW components) evaluated in a "free" and an "ITRF" reference frame. The same 6 stations as in Fig. 3 are shown in the reference network configuration over the same period from 20-22 October 2002 (day of year 293-295). Standard constraints on tropospheric parameter variability are applied in both solutions. Quantification of biases and standard deviations are resumed in Table 2. 
Table 2. Differences of tropospheric parameters between solutions in ITRF and relaxed reference frame (free) for the 6 stations shown in Fig. 4 and the 44 stations used in calculations. Biases and standard deviations for ZTD and gradients components $\left(G_{\mathrm{EW}}\right.$ and $\left.G_{\mathrm{NS}}\right)$ are shown.

\begin{tabular}{lccc}
\hline $\begin{array}{l}\text { GPS } \\
\text { SITES }\end{array}$ & $\begin{array}{c}\Delta \text { ZTD } \\
\text { (ITRF-free) [mm] }\end{array}$ & $\begin{array}{c}\Delta G_{\mathrm{EW}} \\
\text { (ITRF-free) [mm] }\end{array}$ & $\begin{array}{c}\Delta G_{\mathrm{NS}} \\
\text { (ITRF-free) [mm] }\end{array}$ \\
\hline BORD & $4.6 \pm 0.3$ & $-2.3 \pm 1.0$ & $3.2 \pm 0.5$ \\
BANE & $4.0 \pm 0.3$ & $2.5 \pm 0.9$ & $1.4 \pm 0.4$ \\
COLE & $4.1 \pm 0.3$ & $-2.8 \pm 1.0$ & $1.7 \pm 0.5$ \\
MAGE & $4.0 \pm 0.3$ & $-2.7 \pm 0.9$ & $1.5 \pm 0.4$ \\
RSTL & $4.1 \pm 0.3$ & $-2.8 \pm 0.8$ & $2.2 \pm 0.5$ \\
MATE & $4.7 \pm 0.8$ & $-7.7 \pm 2.6$ & $7.2 \pm 2.2$ \\
All sites (44) & $4.3 \pm 0.4$ & $-1.1 \pm 1.3$ & $3.7 \pm 1.2$ \\
\hline
\end{tabular}

Table 3. Sensitivity of ZTD RS to the uncertainties of pressure $(\varepsilon P)$, temperature $(\varepsilon T)$, refractivity constants $\left(\varepsilon k_{1,2,3}\right)$, altitude estimation $(\varepsilon z)$, and all parameters simultaneously $(\varepsilon R S)$. Units are $\mathrm{mm}$.

\begin{tabular}{llrr}
\hline Parameter & uncertainty & \multicolumn{2}{c}{$\begin{array}{c}\text { effect on } \mathrm{ZTD}_{\mathrm{RS}} \\
\text { bias [mm] std [mm] }\end{array}$} \\
\hline$\varepsilon P$ & $2 \mathrm{hPa}$ & 0.2 & 0.7 \\
$\varepsilon T$ & $0.2 \mathrm{~K}$ & 0.5 & 0.4 \\
$\varepsilon k_{1,2,3}$ & Bevis et al. (1994) & 1.9 & 0.2 \\
$\varepsilon z$ & $1-200 \mathrm{~m}$ & 6.3 & 1.3 \\
$\varepsilon \mathrm{RS}$ & all & 9.9 & 3.5 \\
\hline
\end{tabular}

Table 4. Bias $(\Delta)$ and standard deviation $(\delta)$ comparing 61 days of ZTD and vertical position estimates from unconstrained (free) and constrained solutions (ITRF), and ZTD from unconstrained and constrained solutions compared to equivalent ZTD from RS data (21 days). Units are $\mathrm{mm}$.

\begin{tabular}{|c|c|c|c|}
\hline \multicolumn{2}{|c|}{$\begin{array}{c}\text { parameter } 1- \\
\text { parameter } 2\end{array}$} & $\begin{array}{r}\text { bias }(\Delta) \\
{[\mathrm{mm}]}\end{array}$ & $\begin{array}{r}\operatorname{std}(\delta) \\
{[\mathrm{mm}]}\end{array}$ \\
\hline ZTD $_{\text {ITRF }}$ & $\mathrm{ZTD}_{\text {free }}$ & 4.0 & 0.9 \\
\hline UpITRF & $\mathrm{Up}_{\text {free }}$ & 389.0 & 1.3 \\
\hline ZTD $_{\text {ITRF }}$ & $\mathrm{ZTD}_{\mathrm{RS}}$ & 5.4 & 14.1 \\
\hline $\mathrm{ZTD}_{\text {free }}$ & $\mathrm{ZTD}_{\mathrm{RS}}$ & 1.7 & 13.8 \\
\hline
\end{tabular}

been observed for the two month of measurements (see Table 4), with a very small standard deviation of $0.9 \mathrm{~mm}$. This means that the "free" position time series conserves the same shape as the ITRF solution and is not affected significantly by correlation with tropospheric parameter estimations.

\subsection{Tropospheric parameter constraints}

The next test concerns the constraints of the tropospheric parameters. The default values for the initial constraints (on ZTD with $\mathrm{ZC}=0.5 \mathrm{~m}$ and on gradients with $\mathrm{GC}=0.03 \mathrm{~m}$ ) and for the variability (on ZTD and gradients with $\mathrm{ZV}=\mathrm{GV}=0.02 \mathrm{~m} \mathrm{~h}^{-1 / 2}$ ), are commonly used in the positioning step with one ZTD estimated every 2 or $3 \mathrm{~h}$ and one GRAD per day. Keeping this relatively loose value for

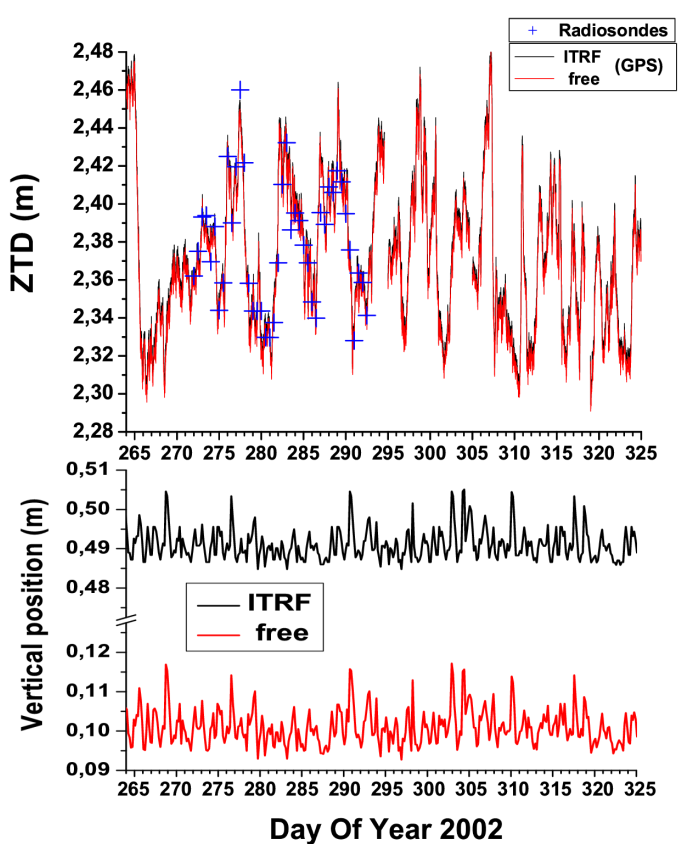

Fig. 5. Time series of ZTD and vertical position estimates for station CDGA over 61 days (from DOY 264 to DOY 325 of 2002), in a free and an ITRF reference frame (red and black lines, respectively). Equivalent ZTD from RS data from the Nîmes station (from DOY 272 to DOY 293 of 2002), represented by crosses, are superposed to the CDGA ZTD solutions. Vertical positions are estimated considering the altitude difference with the Earth centre of WGS84 at $6368137 \mathrm{~m}$.

the variability in our high resolution parameter estimation (one ZTD every $15 \mathrm{~min}$ ) could lead to un-modelled noise being absorbed by the tropospheric parameters. We therefore compare time series of tropospheric parameters (ZTD and GRAD) increasingly constrained to see when significant parts of the signal start to be smoothed out, and when discontinuities at the limit of two sessions start to appear. ZC and GC parameters concern only the adjustment of the first ZTD or GRAD evaluation starting from the a priori value (evaluated with the Saastamoinen 1972 model from a priori 


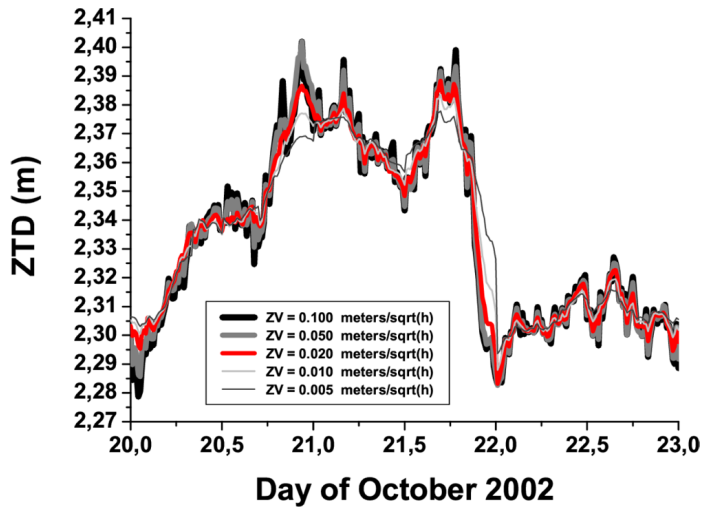

Fig. 6. ZTD at BORD for the time span from 20-22 October 2002 (doy 293-295). Test of the zenith variation (ZV) with values of 0.1 , 0.05, 0.02 (reference), 0.01 and $0.005 \mathrm{~m}$ per sqrt(h) are presented.

information on station altitude, temperature and pressure). They have no influence on the variability of ZTD and GRAD. For good ZTD and GRAD estimations, they should be fixed to a sufficiently large value. We use hereinafter $\mathrm{ZC}=0.5 \mathrm{~m}$ and $\mathrm{GC}=0.03 \mathrm{~m}$.

For three days from 20-22 October 2002, Fig. 6 illustrates the importance of a sufficiently loose Zenith Variation (ZV) parameter to enable the rapid increase or decrease of the ZTD between two successive evaluations. We can see that with loosening the constraints, the ZTD time series is increasingly variable. A maximum of variability is observed for $\mathrm{ZV}=0.1 \mathrm{~m} \mathrm{~h}^{-1 / 2}$. Higher values of $\mathrm{ZV}$ do not result in higher variability of ZTD. As a part of this maximum variability could be due to the absorption of un-modelled noise, limiting $\mathrm{ZV}$ to a value of $0.02 \mathrm{mh}^{-1 / 2}$ represents a compromise, resulting in differences with respect to the "loose" solution of a maximum of $2 \mathrm{~cm}$ in extreme cases. Moreover, imposing higher constraints than $0.02 \mathrm{~m} \mathrm{~h}^{-1 / 2}(0.01$ and $0.005 \mathrm{~m} \mathrm{~h}^{-1 / 2}$, thin grey lines in Fig. 6) induces a jump in the ZTD time series at the session limit at day 22.0, confirming that $\mathrm{ZV}=0.02 \mathrm{~m} \mathrm{~h}^{-1 / 2}$ is probably the optimal choice.

Figure 7 shows the corresponding tests concerning the parameter Gradient Variation (GV) that enables a more or less rapid adjustment of the GRAD components between two successive evaluations. The variability of the gradient time series increases with increasing variations up to $\mathrm{GV}=0.1 \mathrm{~m} \mathrm{~h}^{-1 / 2}$. The value of $\mathrm{GV}=0.02 \mathrm{~m} \mathrm{~h}^{-1 / 2}$ reproduces most of the features depicted by the loosely constrained horizontal gradients, limiting however the amplitude of extreme values. This reference value of $\mathrm{GV}=0.02 \mathrm{~m} \mathrm{~h}^{-1 / 2}$ that is used in this work is probably still conservative, yielding differences with respect to loosely determined gradients of up to $8 \mathrm{~cm}$. However, this also means that the evaluated gradients are most probably significant.

\subsection{One way phase residuals}

In this section, we try to evaluate the information content of another measurement that is interesting for tropospheric studies, the post processed one way phase residuals, the remaining differences between the phase observations and the calculated values after adjustment of all the parameters (3-D positions, ambiguities and tropospheric parameters). These residuals can be extracted for each satellite-station pair for every measurement epoch (i.e. every $30 \mathrm{~s}$ ) in the GAMIT post-processing. This information contains non-modelled error sources which could be, for example, due to multi-path or higher order tropospheric delays. Under the hypothesis that there is no multi-path in our observations and that all other error sources are well modelled in the GAMIT analysis, the residuals could be interpreted as higher order tropospheric delays. Therefore, they could be added optionally to the tropospheric observations ZTD and GRAD being inverted by the tomographic routines.

We can verify the information content of these post-fit phase residuals by comparing two close-by stations, BANE and BERI $(3 \mathrm{~km})$. Figure 8 shows the evolution of the average amount of residuals (indicated as RMS) of six $12 \mathrm{~h}$ sessions per day, throughout the OHM-CV 2002 campaign. We recognise a constant offset between the two curves, with a strong correlation between the variations of the daily average amount of residuals for the two sites. This observation confirms the hypothesis that the residuals are mostly due to tropospheric variability which is closely correlated between the two neighbouring sites.

Furthermore, in Fig. 9 we compare the skyplots of post-fit residuals of these two stations for two $12 \mathrm{~h}$ sessions, one with maximum and one with minimum RMS (16:00-04:00 UTC on day of year (doy) 300-301 and 00:00-12:00 UTC on doy 305 , respectively). The orbital arcs for each visible satellite are represented by the red lines, green and yellow segments indicate positive and negative phase residuals with respect to each satellite at each phase measurement (every $30 \mathrm{~s}$ ). Positive residuals mean the observed phase is more delayed than the theoretical, modelled phase. If this additional delay is due to the troposphere, there is higher refractivity than already modelled by the ZTDs and gradients, and as the most variable tropospheric component is water vapour, this could mean there is an excess of it.

We see that for high RMS conditions the spatio-temporal pattern is similar at both sites and therefore not due to local multi-path effects. Only for low RMS conditions, some decorrelation between the two distributions can be evidenced, that could represent the multi-path pattern of each site.

Our tests suggest that the post-fit residuals seem indeed to be related to higher order tropospheric delay. This delay component is monitored with high spatial and temporal resolution and could contribute to refine the tropospheric observations by GPS. However, its amplitude is relatively low (the red scale tick in Fig. 9 indicates $19 \mathrm{~mm}$ ) with respect to ZTD 
a)

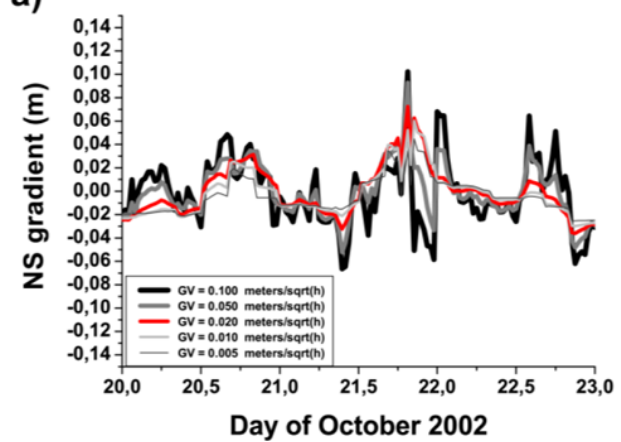

b)



Fig. 7. Time series of horizontal gradient evaluations (GRAD) at BORD for the period from 20-22 October 2002: (a) North-South component; (b) East-West component. Tests of the gradient variation $(\mathrm{GV})$ with values of $0.1 \mathrm{~m} \mathrm{~h}^{-1 / 2}, 0.05 \mathrm{~m} \mathrm{~h}^{-1 / 2}, 0.02 \mathrm{~m} \mathrm{~h}^{-1 / 2}(\mathrm{reference}$ ), $0.01 \mathrm{~m} \mathrm{~h}^{-1 / 2}$ and $0.005 \mathrm{~m} \mathrm{~h}^{-1 / 2}$ are presented.

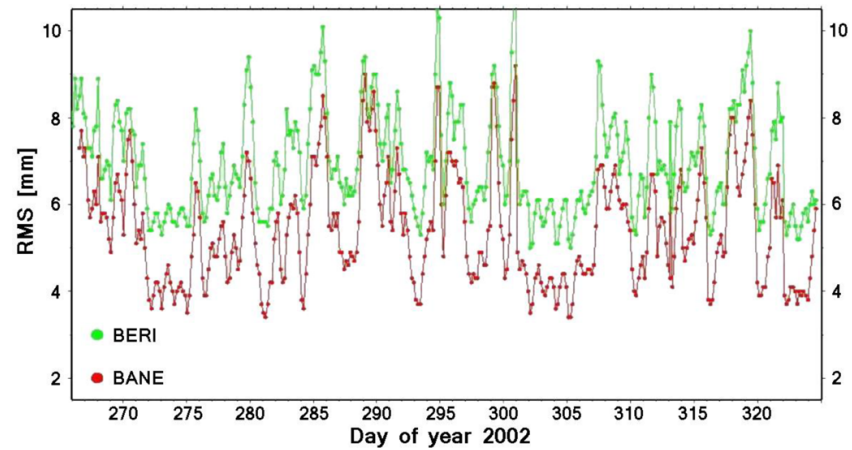

Fig. 8. Time evolution of the average amount of post-fit phase residuals (RMS) per $12 \mathrm{~h}$ session (6 evaluations per day) throughout the measurement campaign in autumn 2002, for the two close-by stations BANE and BERI.

and gradients. Figure 9 shows that residuals can reach $20 \mathrm{~mm}$ at zenith and $50 \mathrm{~mm}$ under low elevation angles $\left(10^{\circ}\right)$, while gradients of more than $150 \mathrm{~mm}$ can be observed under $10^{\circ}$, and the wet (and more variable) contribution of ZTD is of the order of $200 \mathrm{~mm}$ at zenith, and about $1200 \mathrm{~mm}$ under $10^{\circ} \mathrm{el}-$ evation. Including post-fit residuals in the tropospheric delay measurements has therefore a contribution of a maximum of $5 \%$ with respect to ZTD evaluations, and presents some risk of increasing noise in the tropospheric estimates due to the level of multi-path and other un-modelled signals persisting in the residuals.

\section{Tropospheric parameters from final solution}

\subsection{ZTD and gradients}

Zenith total delays (ZTD) and horizontal gradients (GRAD) have been established according to the above mentioned strategy, at $15 \mathrm{~min}$ and $30 \mathrm{~min}$ intervals, respectively. They are presented in Fig. 10 (ZTDs) and Fig. 11 (gradients) for 18



Fig. 9. Skyplots of post-fit residuals for the two sites distant of $3 \mathrm{~km}$ : BANE (right column) and BERI (left column), during high (upper line) and low (lower line) RMS conditions. Post-fit residuals are evaluated at each measurement interval (every $30 \mathrm{~s}$ ), during $12 \mathrm{~h}$ sessions on days 300 (high RMS) and 305 (low RMS).

stations from the local tomographic network. The ZTD time series show high correlation, however with a constant offset, due to altitude differences between the stations, the lowest stations displaying the highest values of ZTD. The gradients show some clearly correlated features in the local network, but also some dispersion when different stations of the small scale network measure different gradients. This means that the spatial scale over which the same horizontal tropospheric gradient can be observed could be estimated to less than $20 \mathrm{~km}$. This also indicates that we are able to resolve a spatial variability of tropospheric delay inside the local network, despite its limited surface. 


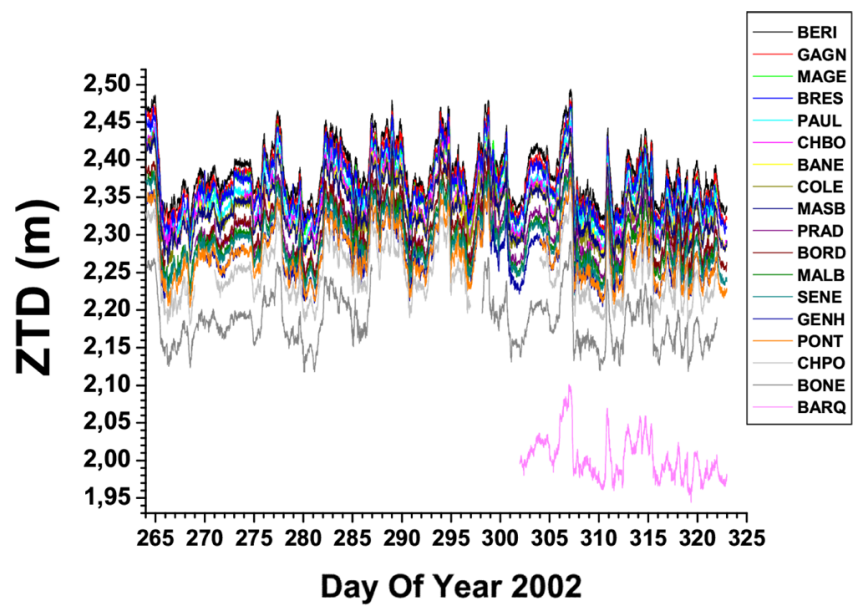

Fig. 10. ZTD time series for the 18 stations of the local network over the total observation span (doy 264 to 325 of 2002).

When representing 2-D fields of ZTD, the signal due to the underlying topography prevails over the temporal variations of ZTD as reflected by the vertical offset between the individual station time series on Fig. 10. This is due to the strong altitude dependence of ZTD, in particular through its hydrostatic component (ZHD), but also its wet component (ZWD) which decreases with altitude. Indeed, the ZHD difference between the lowest and the highest station of our local network (BERI at $195 \mathrm{~m}$ and BARQ at $1471 \mathrm{~m}$ ) can be calculated employing the hydrostatic equation and the ZHD dependency on surface pressure (Eq. 2), and yields values of the order of $30 \mathrm{~cm}$ which is large with respect to the roughly $15 \mathrm{~cm}$ temporal variability of ZHD at individual sites throughout the experiment (Fig. 10).

Hence, an altitude correction for the ZTD measurements at individual sites must be applied in order to show the spatial ZTD variations in the network independently of the topography that is the prevailing signal in Fig. 12a. One approach is to convert the ZTD measurements made at different altitudes to the sea level by adding the Zenith Hydrostatic Delay contribution between sea level and the station altitude. This approach neglects however the contribution of water vapour that also decreases exponentially with altitude. Therefore, we propose to represent relative ZTD fields, subtracting the average ZTD value over the two months' period from each station's ZTD time series. Topography-corrected, relative ZTD measurements can be represented on a horizontal map using a classic bilinear interpolation (Fig. 12b) or an interpolation scheme that takes also into account the horizontal gradients (Hermite interpolation, Fig. 12c). A presentation of this method of interpolation can be found in Sandwell (1987). Our study uses the v4 biharmonic matlab routine. Automatically, this routine considers also ZTD and gradients uncertainties and minimises their effects to obtain the final global Hermitian interpolant. Note that to be taken into account in interpolation, gradient components (provided at $10^{\circ}$ of elevation) have been mapped in the zenith direction using the Niell's mapping function (NMF, 1996). The ZTD maps of Fig. 12b and c demonstrate the benefit of including the horizontal gradients in the interpolation scheme in order to resolve more detailed features (see Brenot et al., 2013). This is true although the current GPS network has small inter-station distances (less than $10 \mathrm{~km}$ ) and, hence, the spatial variation of ZTD should coincide with the horizontal gradients evaluated at single stations (Walpersdorf et al., 2004). As in this dense network, horizontal delay gradients seem to provide local information that is independent from linear differences between neighbouring station ZTDs, this seems to indicate that GPS gradients are sensitive to small-scale tropospheric variability over less than $10 \mathrm{~km}$. Therefore, in networks with larger inter-station spacing $(>20 \mathrm{~km})$ the addition of horizontal gradients in the interpolation scheme should becomes essential as the spatial ZTD variations are not redundant anymore with single site horizontal gradients.

\subsection{ZWD and PWV}

The 5 meteorological stations deployed in the local network (Fig. 1) and measurements from the operational synoptic network (Météo-France) are used to estimate surface pressure at all sites by converting hydrostatically and interpolating the pressure measurements to the station heights. With these values, zenith hydrostatic delay (ZHD) can be evaluated at each local station and subtracted from the GPS measured ZTDs to obtain the corresponding zenith wet delays (ZWD).

Likewise, the ZWD can be converted into precipitable water vapour (PWV) according to Eqs. (6) and (9) using interpolated surface temperature estimates obtained from the same meteorological station network and taking into account the altitude differences with a constant temperature gradient of $0.006 \mathrm{~K} \mathrm{~m}^{-1}$. As shown above, this procedure of extraction of PWV from ZTD measurements implies the use of several empirical formulations. The total error budget for GPS PWV estimation is however less than $1 \mathrm{~mm}$, and has been detailed in Brenot et al. (2006). For example, Fig. 13 shows the time series of PWV estimates at the GPS stations of the local network for the total duration of the measurement campaign.

One of the goals of our work is to provide estimates of water vapour based on GPS measurements and compare them with precipitation observations in order to investigate possible precipitation precursors in the water vapour field evolution. Figure 14 presents the PWV time series for one of the GPS stations (BORD, in the centre of the network) and compares them with time series of integrated radar reflectivity obtained with the meteorological radar of Bollène (location see Fig. 1), as well as hourly accumulated rain fall from a network of rain gauges available in the study area. These comparisons between three types of independent measurements provide interesting information although the radar reflectivity and rain fall accumulation measurements are area 

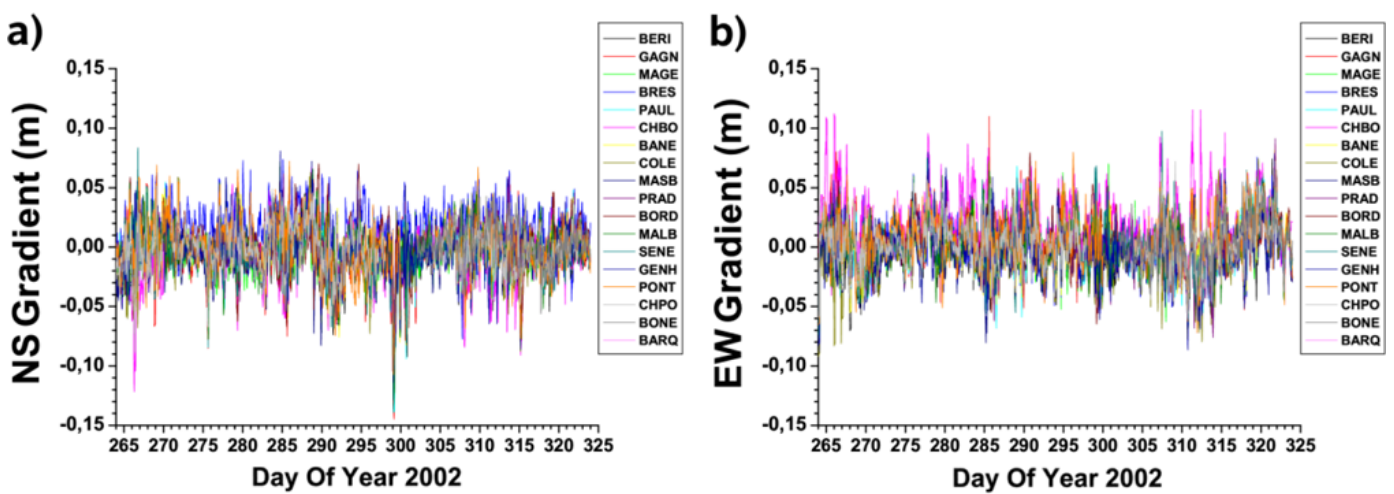

Fig. 11. Time series of horizontal tropospheric gradients for the 18 stations of the local network over the total observation span (doy 264 to 325 of 2002). (a) NS component; (b) EW component.

averages while the PWV corresponds to a single GPS station within the network. One can notice a strong correlation between precipitation and radar reflectivity. Likewise, there is an indication that water vapour content is high before and during the rain events, sometimes as much as $15 \mathrm{~mm}$ above clear weather values, but not all PWV peaks lead to precipitation. Also, once the heaviest rainfall has started, as shown by radar and rain gauge data, the tropospheric water vapour content drops rapidly. This means that PWV decreases even before the end of the rain episode, as illustrated on doy 294, where the water vapour content drops at 19:00 UTC while precipitation continues until 21:00 UTC.

\subsection{2-D maps of PWV}

The corresponding PWV observations can also be shown as 2-D maps. The distribution of PWV measured by a GPS network is still highly correlated with the topography: indeed, the vertical water vapour content distribution follows an exponential law with a scale height of about $2-3 \mathrm{~km}$. Thus, as already discussed for the ZTD maps, the main feature on PWV maps is largely driven by the orography, with PWV variations in time that are comparatively weak with respect to this predominant signal. Hence, to better visualize the variations of the PWV field, we have chosen here to present it in a differential way with respect to a reference epoch, such that only the relative evolution is being considered. Our study period is the rain event of 21 October, and we selected the PWV field of 8 October at 00:00 UTC as the reference field as it corresponds to a stable situation before the rain episode.

For sparse regional networks, the wet gradients can be included in the PWV interpolation (for example, in Hermite interpolation) to increase the resolution of the PWV field (Champollion et al., 2004). However, given the proximity of the stations in our current network, we opted for a bi-harmonic spline interpolation (Sandwell, 1987). Furthermore, in order to avoid spurious extrapolated results outside of the area covered by the GPS network, a mask is applied to limit the results to the interpolation zone. Figure 15a presents the evolution of the differential PWV field maps over $1 \mathrm{~h} \mathrm{ev-}$ ery $15 \mathrm{~min}$.

The period from 19:15 to 20:15 UTC on 21 October corresponds to a rapid decrease of PWV over the network, as already evidenced by the PWV time series of BORD shown in Fig. 14. This phenomenon is well reproduced by the successive PWV maps where the compilation of the observations at the different GPS sites adds spatial information. We can resolve that the troposphere dries out from west to east after 19:45 UTC. These detailed measurements will be confronted in a later section with results from the tomographic inversion of the GPS data.

\subsection{Wet gradients and slant wet delays}

Considering the total delay maps, we have shown that including horizontal delay gradients in the ZTD interpolation could increase the spatial resolution even in our small scale network. Here we separate the wet contribution from the total delay gradients to construct anisotropic wet delay observations at each GPS site, the slant wet delays (SWD). While for the total zenith delay the hydrostatic contribution is prevailing, the delay gradients are mainly related to delay anisotropies created by the local variability of water vapour. Nevertheless, it is still critical to remove the hydrostatic part of the gradients when gradients are included in the reconstruction of wet delay. In our case, the surface pressure observations within the dense network are used to separate the wet contribution from the total horizontal gradients evaluated in the GPS analysis. First, we establish a hydrostatic gradient by fitting a plane through the pressure measurements at each measurement epoch. This hydrostatic gradient is then subtracted from the total gradients estimated by GPS to obtain the wet gradients (Fig. 16). The hydrostatic gradients have typical amplitudes of a few $\mathrm{mm}$ and can reach maximum amplitudes of 5 to $10 \mathrm{~mm}$ which represents up to $25 \%$ of the observed total gradients with typical values of $20 \mathrm{~mm}$ and maximum values of $40 \mathrm{~mm}$ (Fig. 16). 

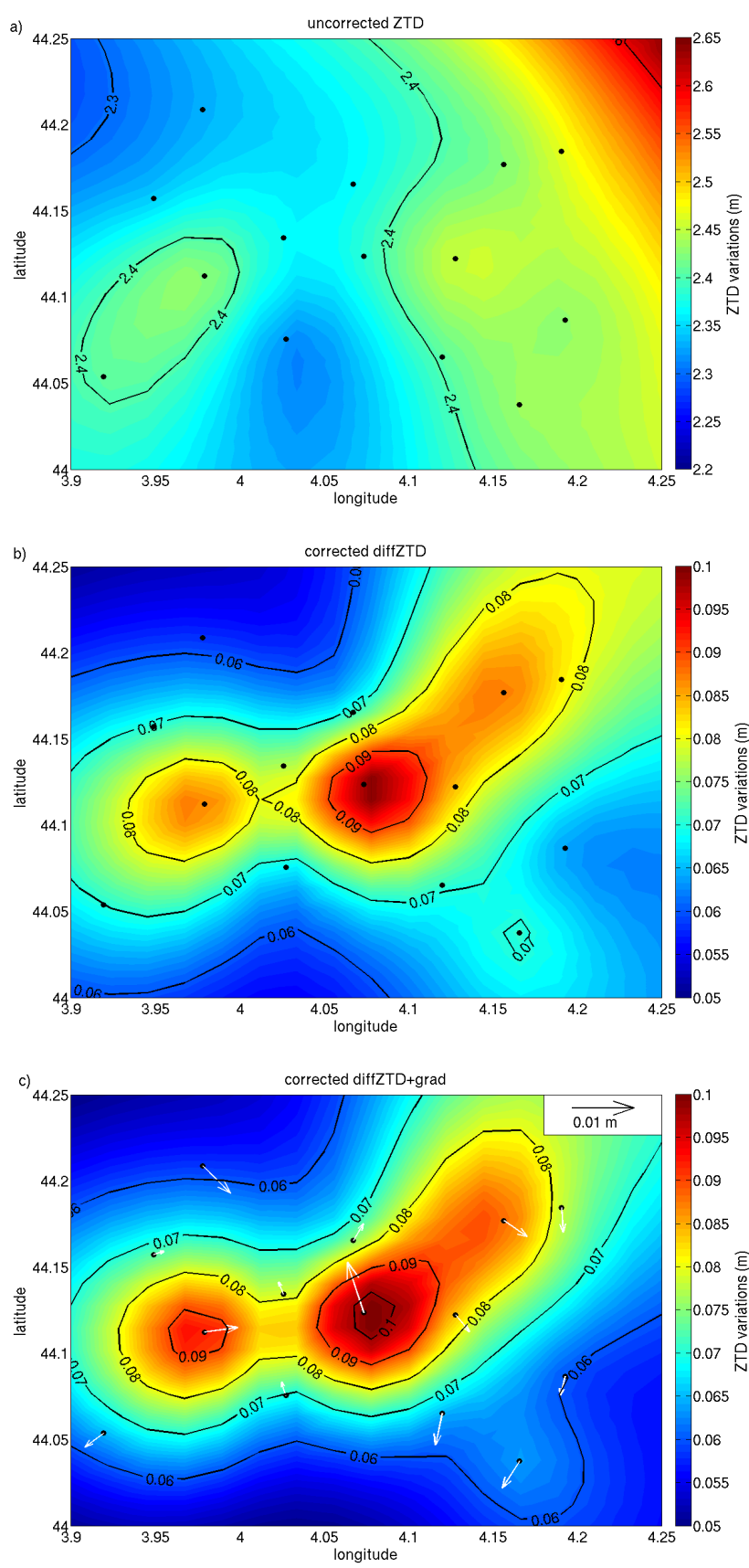

Fig. 12. Instantaneous 2-D field of zenith delay variation (21 October 2002, at 19:15 UTC), interpolated from measurements at GPS station locations uncorrected (a) and topography-corrected (b and c) for station altitude by subtracting the average ZTD over the two months measurement campaign. The ZTD field (b) is established without and (c) with integrating horizontal delay gradients. Site locations are indicated by stars, vectors correspond to horizontal gradients (scale vector corresponds to $0.01 \mathrm{~m}$ ). The colour code indicates ZTD variations in $\mathrm{m}$.

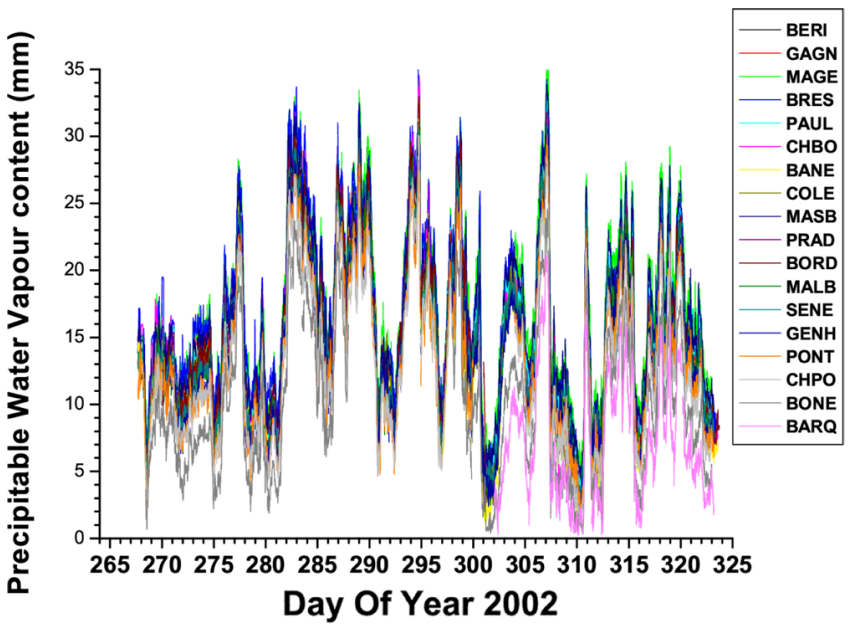

Fig. 13. PWV time series for BORD station from the local network, from 20-22 October 2002 (doy 293 to 295), indicated by the red line. For comparison, domain integrated reflectivity from the meteorological radar in Bollène is shown in green (in arbitrary units), and accumulated hourly rainfall from the Météo-France rain gauge network is indicated by blue histograms.

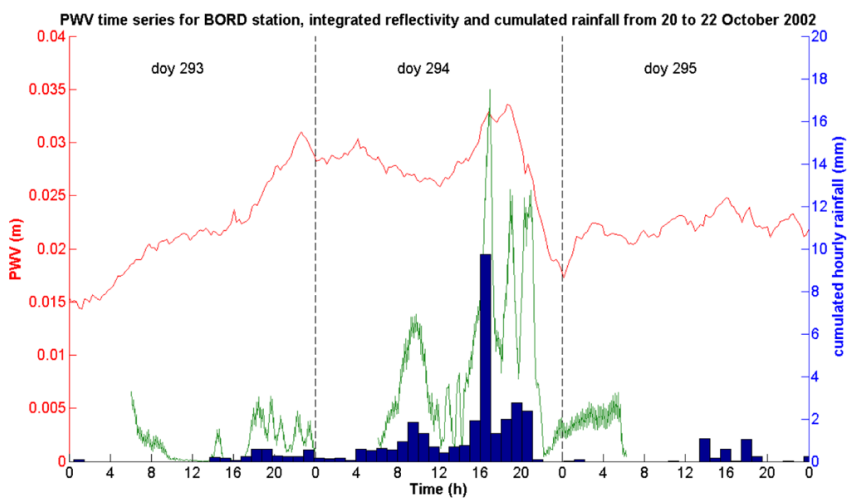

Fig. 14. PWV time series for 16 stations of the local network for the total measurement campaign in 2002.

In our study, wet gradients (total-hydrostatic) are combined with ZWD to evaluate SWDs along individual lines of sight between a ground station and the GPS satellites. This anisotropic quantity SWD will be used in the tomographic inversion. Our methodological tests presented in Sect. 4 permit a rigorous estimation of the uncertainty of SWD that will have a direct impact on the possible precision of their tomographic inversion. If we consider maximum errors from Sect. 4 (adding biases and standard deviations), we obtain a maximum ZTD error of $10-15 \mathrm{~mm}$ corresponding to $60-90 \mathrm{~mm}$ at $10^{\circ}$ of elevation, a maximum GRAD error of $30-50 \mathrm{~mm}$ at $10^{\circ}$ and with the largest possible residuals of $140 \mathrm{~mm}$ under $10^{\circ}$. Hence, the precision of SWD estimation (summarized $230-280 \mathrm{~mm}$ from a typical value of $\sim 1500 \mathrm{~mm}$ for SWD at $10^{\circ}$ ) is about $15-20 \%$. Assuming the inversion of SWD obtained in the OHM-CV 2002 

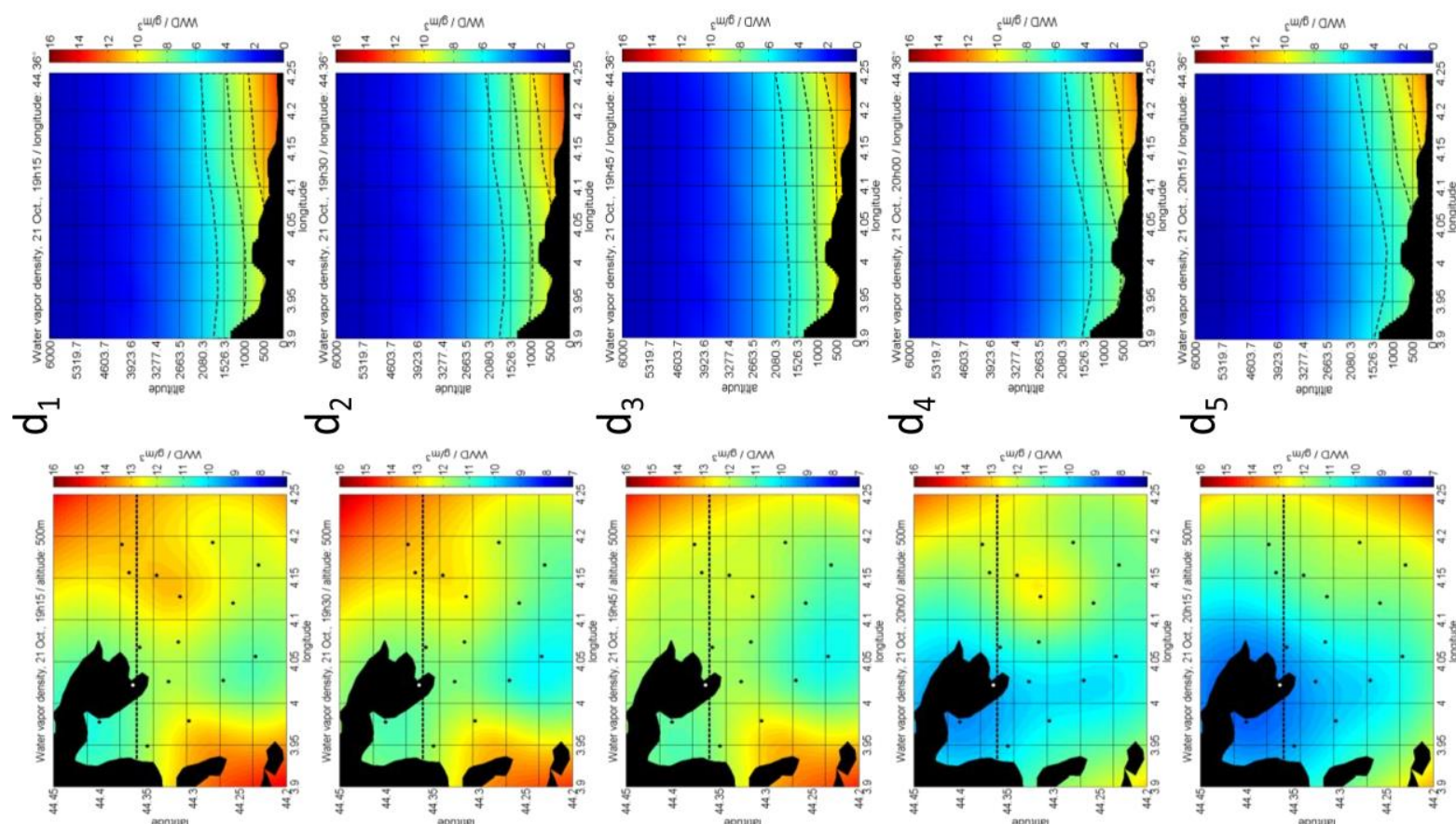

ঠ
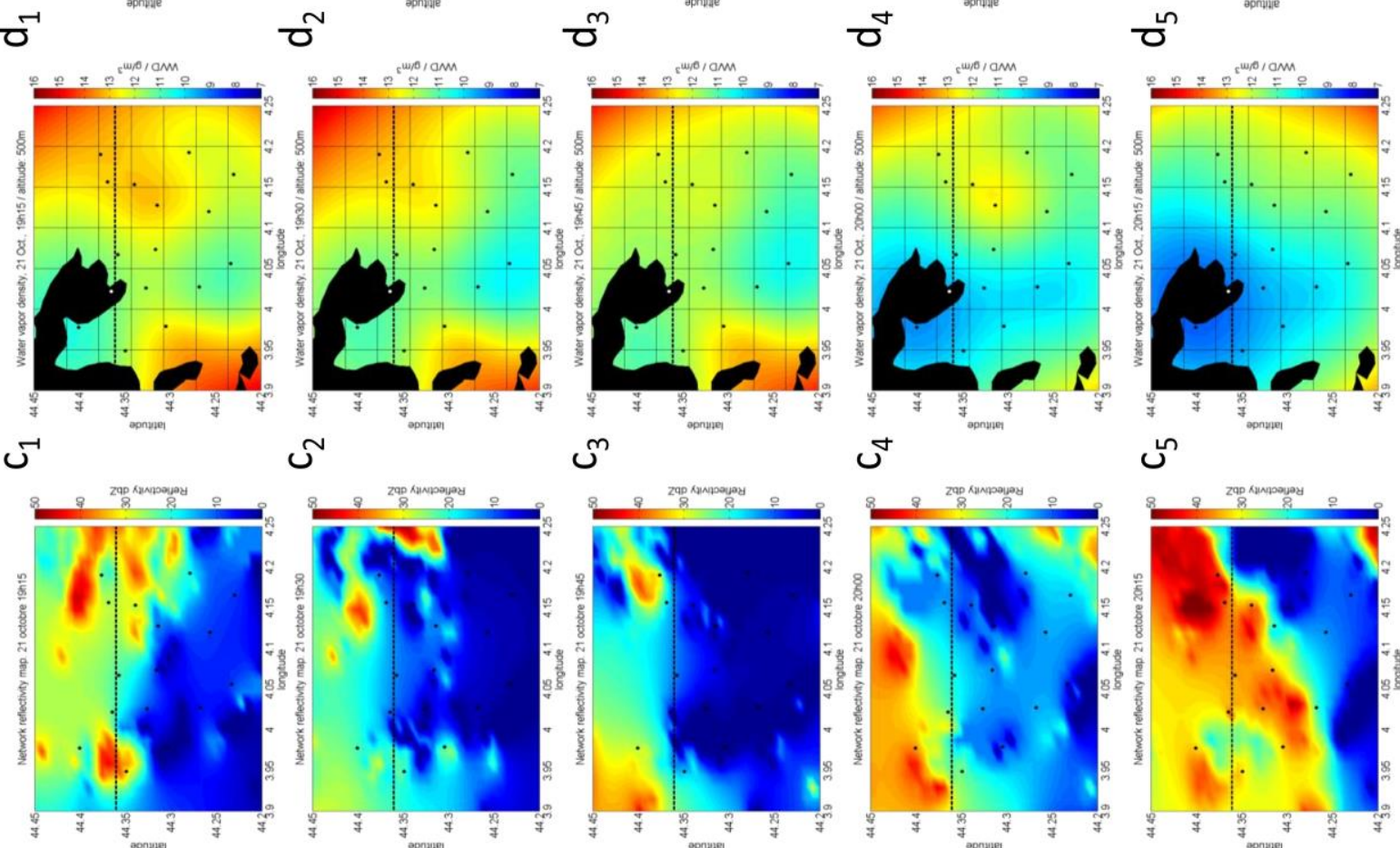

v

ஸ

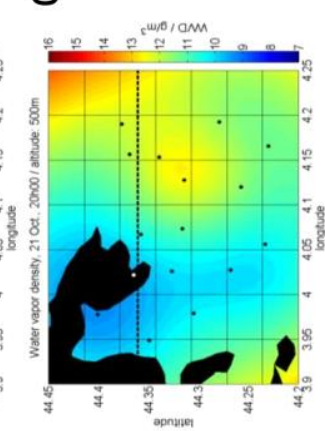

ज

ง
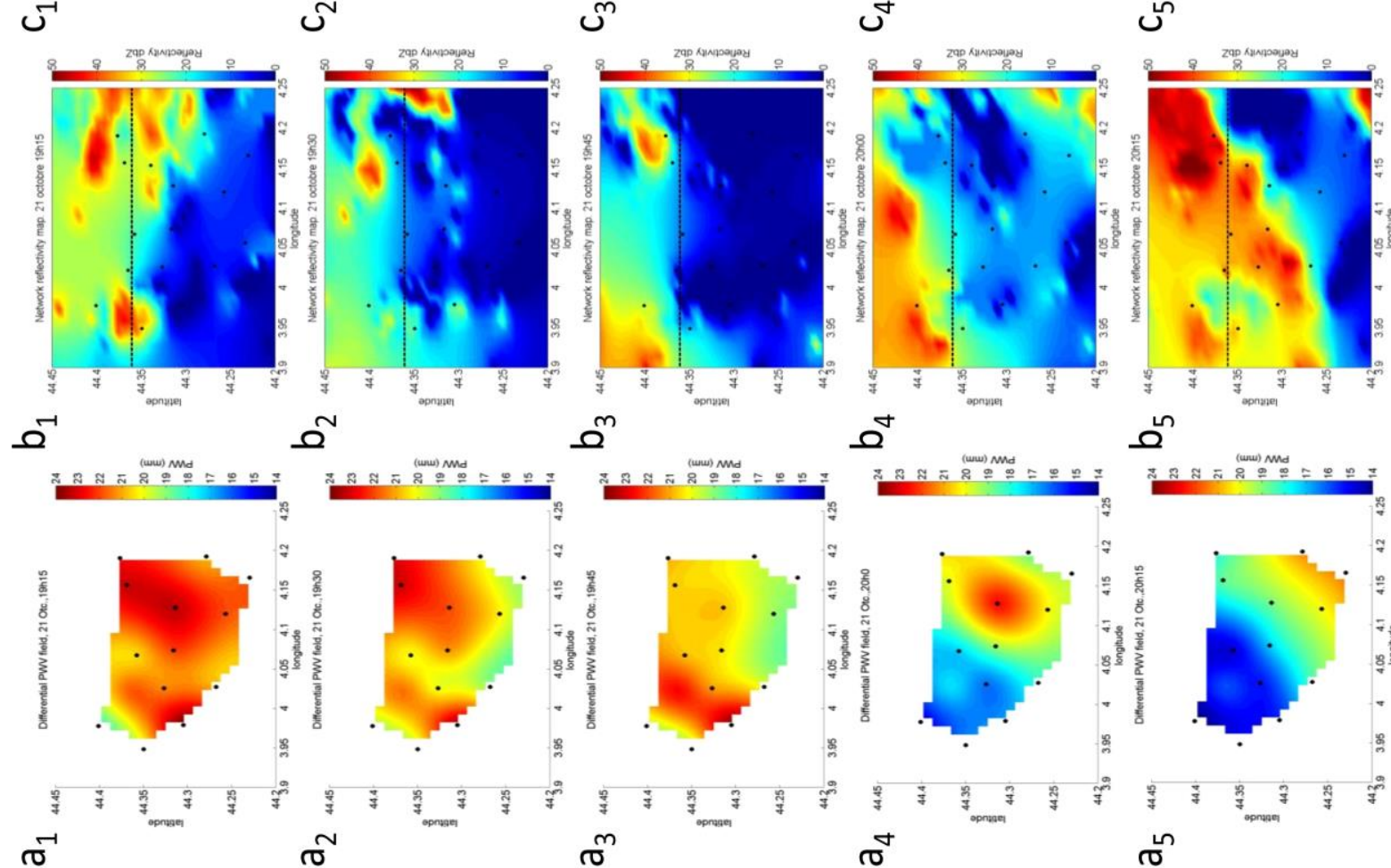

$\pi^{m}$

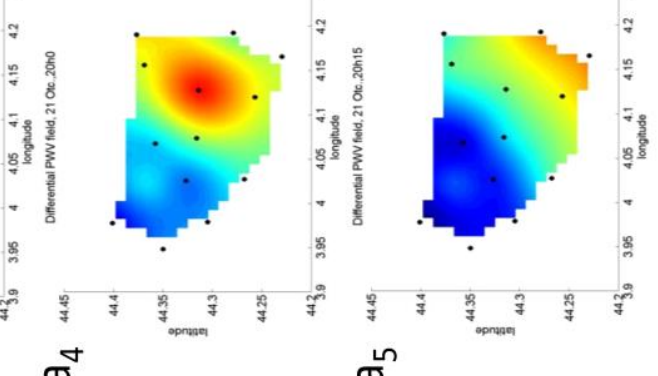

Fig. 15. (a) The differential PWV field (with respect to the epoch on 8 October at 00:00 UTC) over our dense local network on the 21 October 2002 from 19:15 to 20:15, in 15 min time steps. The units are mm; (b) Corresponding radar reflectivity fields in dbZ from the Bollène Radar; (c) Corresponding water vapour density $\left(\mathrm{g} \mathrm{m}^{-3}\right.$ ) on horizontal cross sections (altitude $500 \mathrm{~m}$ ). The dashed line indicates the location of the (d) profile; (d) Water vapour density $\left(\mathrm{g} \mathrm{m}^{-3}\right.$ ) on vertical cross sections (west-east oriented). Lines of constant water vapour density of 10,8 and $6 \mathrm{~g} \mathrm{~m}^{-3}$ are represented by dashed lines. In (a), (b) and (c), the black dots indicate GPS station positions. In (c) and (d), the black lines represent the voxel limits, and the relief is indicated in black. The dashed line in (b) and (c) indicates the profile shown in (d). 

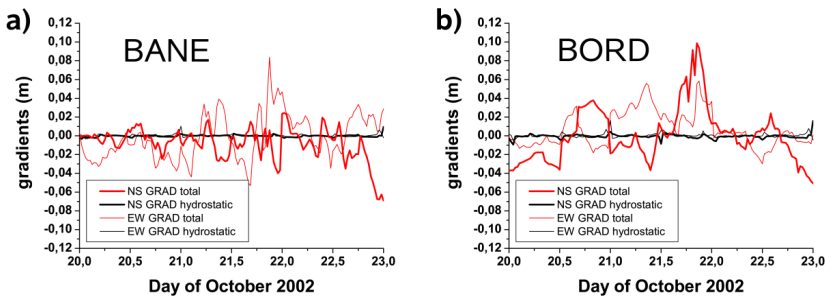

Fig. 16. Total and hydrostatic horizontal gradients (NS and EW components), for station (a) BANE and (b) BORD over the period from 20 to 22 October (doy 293-295).

network by our tomographic routines produces an equivalent relative error in water vapour density, we can evaluate uncertainties in the order of $1.5-2.0 \mathrm{~g} \mathrm{~m}^{-3}$ for average densities of $10 \mathrm{~g} \mathrm{~m}^{-3}$.

\subsection{One way phase residuals}

A third contribution to the water vapour observations by GPS (apart from ZWD and wet gradients) could potentially be found in the one way phase residuals. In Sect. 4, we have shown that a part of the residuals evaluated at individual GPS stations could effectively be related to higher order tropospheric delay linked to atmospheric water vapour variations. For the time being, a clear separation of the tropospheric content in the phase residuals has not been achieved. Comparisons with high resolution atmospheric models or measurements at GPS sites co-located with pointed water vapour radiometers or lidars could help identifying more clearly the signature of higher order tropospheric delay in the phase residuals. The high temporal and spatial resolution of the one way phase residuals (every $30 \mathrm{~s}$ for every recorded satellite) gives them a high information potential, although their amplitude is relatively small with respect to ZTD and gradients. Including them in the tomographic inversion is an option in our software, but tests with and without using residuals did not yield significantly different solutions. Possible correlation between phase residuals and meteorological situations has already been mentioned by Champollion et al. (2004). In Fig. 17, we present the one way phase residuals for station BANE covering the 21 October from 12:0024:00 UTC, including the rain event monitored by the PWV fields in Fig. 15a (from 19:15 to 20:15 UTC). Increased residuals reaching $20 \mathrm{~mm}$ at zenith are observed from 16:00 to 22:00 UTC, covering the period of heaviest rain above the network. Not including them in the SWD evaluation creates less than about $10 \%$ error. The total horizontal gradients (that are in this case similar to the wet gradients as shown in Fig. 16) added on each of the two-hourly sky-plots are coherent with the PWV field, changing to easterly directions after 18:00 UTC.
This Sect. 5 has summarized the different tropospheric observations that can be extracted from our GPS measurement campaign (ZTD, ZWD, PWV, total and wet GRAD, one way post-fit phase residuals) and illustrated their individual information content at the example of the rain event of 20 22 October 2002. In the following section, we try to exploit their spatio-temporal resolution in an optimal way using tomographic inversion in order to further investigate the relationship between the water vapour distribution and the precipitation systems.

\section{GPS water vapour tomography and comparison to rain fields}

The data observations used for the tomographic inversion are the slant wet delays. They will be later converted into slant precipitable water vapour following a similar conversion strategy as the conversion ZWD to PWV mentioned in Sect. 3. For convenience, we will express hereafter slant precipitable water vapour in terms of SIWV (Slant Integrated Water Vapour), equivalent but more widely used in the literature.

For each GPS station, the corresponding ZWDs and wet components of the gradients are projected into the direction of the different satellites in sight using the appropriate mapping function to produce the SWDs (Niell, 1996; Chen and Herring, 1997). One way post-fit phase residuals have not been considered in this work. The original measurements of ZTD and horizontal gradients are extracted at an interval of $15 \mathrm{~min}$ from their time series. The number of observations at one instant depends mainly on the number of stations and the number of satellites visible at each of the stations. In our case, due to the network configuration, we have roughly 130 SWDs at each epoch, a relatively small number to constrain a 3-D field with good spatial resolution. Furthermore, the lines of sight (LOS) from the stations to the satellites in a small network are almost parallel, therefore only a small number of volume elements (voxels) above the network will have intersecting rays to provide redundant information about the water vapour distribution. To increase the number of observations, we can include several successive evaluations in one inversion. For instance, we can chose to calculate one inversion over an interval of $15 \mathrm{~min}$ with 30 successive ZTD and gradient evaluations instead of a single one by interpolating the tropospheric parameter estimations every $30 \mathrm{~s}$. This leads to a total of roughly 4000 SWD observations per inversion. Over a longer time span than $15 \mathrm{~min}$, the GPS satellites progress on their orbits and new geometric information is added. However, the unstable state of the atmosphere is the limit of this ray "adding" method. Generally, considering water vapour, the atmospheric state will have changed significantly after $2 \mathrm{~h}$, especially if one is interested by meteorological events such as frontal passages or convective situations. Thus, the time interval of $15 \mathrm{~min}$ 


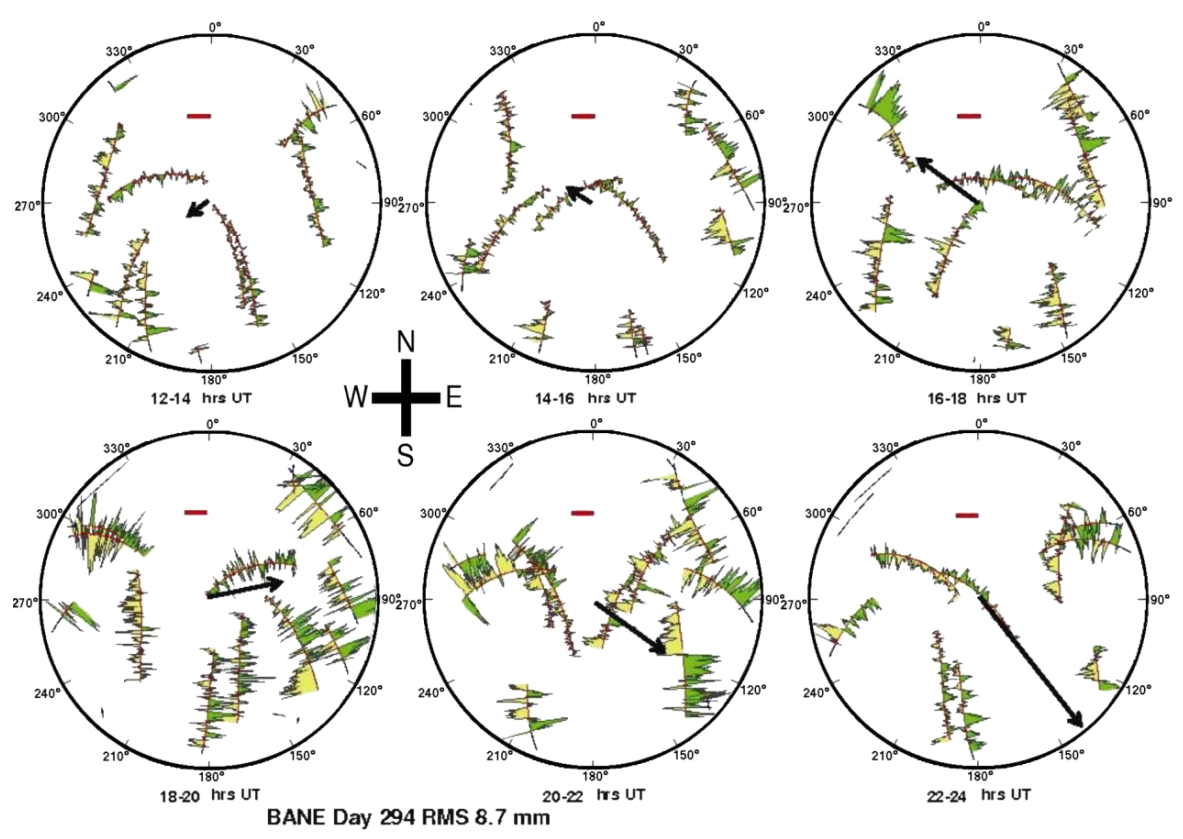

Fig. 17. Post-fit one way phase residuals for station BANE on 21 October 2002 (doy 294), from 12:00 to 24:00 UTC. Black arrows show the average total horizontal gradient for each $2 \mathrm{~h}$ interval (pointing towards maximum delay). Gradient values cover amplitudes from $6 \mathrm{~mm}$ (12:00-14:00 UTC) to $37 \mathrm{~mm}(22: 00-24: 00$ UTC).

between successive evaluations of ZTD appears as a compromise between short intervals with few observations within one inversion, but containing highly correlated observations in successive evaluations (monitoring a same state of the troposphere), and long intervals resulting in an increased number of observations in one inversion, but uncorrelated observations (monitoring an evolving state of the troposphere).

To obtain the three dimensional water vapour field above the GPS network from SWDs, the volume above the network that is crossed by the LOS toward the satellites is divided into volume elements called voxels. The inversion of SIWV contributions (converted from SWDs) in each individual voxel evaluates a quantity of water vapour density (dimensional considerations are given hereafter). We used a least square solution (Menke, 1989) to resolve the following inverse problem (Tarantola, 2005):

$d=G \times m$,

where $d$ represents the data (SIWV), $G$ the model we will use; i.e. the linear operator providing the length distribution of SIWV in each voxel, and $m$ corresponds to our results, in our case, the water vapour density. The solution to this linear problem is given by Menke (1989) and Tarantola (2005):

$$
\begin{aligned}
& m^{\text {res }}=m_{0}+\left(G^{t} \cdot W_{\mathrm{GPS}} \cdot G+\alpha^{2} \cdot W_{\text {Model }}\right)^{-1} \cdot G^{t} \\
& \quad \cdot W_{\mathrm{GPS}} \cdot\left(d-G \cdot m_{0}\right),
\end{aligned}
$$

where $m^{\text {res }}\left(\mathrm{g} \mathrm{m}^{-3}\right)$ is the resulting water vapour density, $m_{0}$ $\left(\mathrm{g} \mathrm{m}^{-3}\right)$ is an a priori solution or first guess that is needed in order to solve underdetermined problems. This first guess is an exponential decrease based on standard atmospheric values adjusted with the average IWV measured by GPS throughout the domain. Note that the tomographic retrievals are sensitive to this first guess showing an uncertainty up to $2 \mathrm{~g} \mathrm{~m}^{-3}$ for the low troposphere (Reverdy, 2008). $W_{\mathrm{GPS}}$ $\left(\mathrm{m}^{4} \mathrm{~g}^{-2}\right)$ corresponds to the weighting matrix or the inverse of the variance/covariance matrix of the data errors i.e. $W_{\mathrm{GPS}}=\left(C_{\mathrm{GPS}}\right)^{-1} \cdot W_{\text {model }}\left(\mathrm{m}^{6} \mathrm{~g}^{-2}\right)$ corresponds to the matrix of the variability of the model around the a priori values. $d$ represents the SIWV $\left(\mathrm{g} \mathrm{m}^{-2}\right)$ and $G(\mathrm{~m})$ is the model described above. The subscript $t$ in this equation denotes transpose. $\alpha$ (dimensionless) is a weighting coefficient which can give more weight to the error on the data or on the estimation. The higher $\alpha$, the more we consider the initialization as a solution and the lesser weight is given to the data and inversely.

The GPS station network implemented offers an adequate coverage of the campaign domain and allows us to perform high resolution tomography thanks to its somewhat regular and dense geometry with station spacing of roughly $5 \mathrm{~km}$ between GPS sites. Vertically, the GPS stations cover an interesting altitude range from $195 \mathrm{~m}$ to $848 \mathrm{~m}$ (the highest station BARQ at $1471 \mathrm{~m}$ altitude was operational only after doy 300). Hence, differencing the PWV evaluations between different altitudes and implementing SWDs down to a cutoff angle of $10^{\circ}$, we obtain a good vertical restitution of the lower part of the atmosphere. 
In our work, we have used a $7 \times 7 \mathrm{~km}$ voxel grid to cover the horizontal inversion domain, choosing the horizontal dimension of the voxel to be comparable to the average distance between the GPS stations $(5 \mathrm{~km})$. The vertical voxel size was set to $500 \mathrm{~m}$ for the lowest layer with an exponential increase with height up to $12 \mathrm{~km}$ where water vapour is deemed negligible. This allows taking into account the decrease of water vapour density as the altitude increases. For display, the tomography results are smoothed across voxel boundaries using a classical cubic spline interpolation scheme onto a denser grid mesh.

As for the 2-D PWV fields, the tomographic restitution is most accurate within the area delimited by the GPS stations while the parts of the inversion domain outside of the network boundaries are affected by the lack of information (i.e. divergent water vapour density results due to the extrapolated PWV field used for initialisation). Likewise, the mean accuracy we can expect for the water vapour density estimates with such a small and dense network is on the order of $\pm 1 \mathrm{~g} \mathrm{~m}^{-3}$ (Reverdy, 2008). This value could be improved by adding GPS stations, especially at the edge of the network to decrease boundary effects.

Based on the grid configuration described above, Fig. 15c and $d$ show the results of the tomographic inversion of the GPS observations in terms of water vapour density on selected horizontal and vertical cross sections. GPS tomography allows retrieving well-defined and small-scale structures of water vapour. With enough data for the inversion, we can obtain a horizontal resolution somewhat better than the mean distance between stations. In this study, we reached a resolution of about $5 \mathrm{~km}$ in horizontal and $500 \mathrm{~m}$ in the first vertical levels. The evolution of the $500 \mathrm{~m}$ level water vapour density obtained by the tomographic inversion, shown in Fig. 15c, can be compared to the corresponding PWV fields presented in Fig. 15a. While the PWV field is constituted by integrated values attributed to the vertical direction above each station, the tomographic water vapour field contains additional information about the water vapour distribution, horizontally in between the individual stations, and to some extent vertically. Hence, in the $500 \mathrm{~m}$ tomographic cross section, the quantification of water vapour in the space between the stations has constraints that are more meaningful than the simple interpolation used for the PWV field. Therefore, some details of the west-to-east drying phases of the atmosphere above the network for the 21 October 2002 rain event are found in the $500 \mathrm{~m}$ level of the water vapour density field that could not be resolved using only PWV observations. In particular, the field at 20:00 UTC shows that the drying in the $500 \mathrm{~m}$ layer starts close to the topographic high in the NW of the network and extends then into the NNW-SSE oriented valley to the SSE, before generalising in the NW of the network at 20:15 UTC. At the same time, the PWV field indicated more roughly a global N-W to S-E evolution corresponding to the background synoptic forcing. Between 19:45 and 20:15 UTC, the water vapour density at $500 \mathrm{~m}$ dropped significantly from $\sim 12 \mathrm{~g} \mathrm{~m}^{-3}$ to $\sim 9 \mathrm{~g} \mathrm{~m}^{-3}$ in the NW of the network.

Likewise, the tomography retrieved vertical cross sections of Fig. 15d show a marked depletion of water vapour density to the west domain at 20:00 UTC, in agreement with the horizontal water vapour fields. In the west of the cross section, the $6 \mathrm{~g} \mathrm{~m}^{-3}$ line dropped from $\sim 1700 \mathrm{~m}$ at 19:45 to $\sim 1200 \mathrm{~m}$ at $20: 15$, while the vertical structure of water vapour density remained unchanged in the eastern part.

The detailed three dimensional description of the atmospheric water vapour distribution and its evolution provided by tomography can also be used to establish possible correlations between the local 3-D water vapour field above the GPS network and the 3-D rain field measured by the volume scanning radar at Bollène, trying to identify mechanisms of evaporation and condensation in the context of convective rainfall. The detailed comparison of simultaneously measured 3$\mathrm{D}$ water vapour density and rain fields above the OHM-CV GPS network will be the object of a subsequent dedicated publication. Here, we restrict our analysis to the comparison of 2-D fields for a first approach. In Fig. 15b, we present the Bollène radar 2-D reflectivity fields corresponding at a $0.8^{\circ}$ elevation scan over the same domain than the GPS network and for the same time frames as the tomographic water vapour fields at $500 \mathrm{~m}$ (Fig. 15c). The rain event in the evening of 21 October 2002 corresponds to a warm front passage. Comparing the two types of measurements, it appears that there are high water vapour contents in the lower atmosphere just ahead (to the SE) of the precipitation system which actually develops predominantly towards those areas of higher water vapour content. While the front (that is coinciding with the delimitation of the precipitation zone) passes across the network, a marked depletion of water vapour density is noticed, with water vapour contents remaining low at the locations of the rainfalls. Therefore, one could make the assumption that the low-level water vapour is either condensed into liquid water (droplets) through warm frontal embedded convection processes, washed out by the falling rain drops through accretion-like processes (Van Baelen and Penide, 2009; Van Baelen et al., 2011), or replaced by dry air from above advected by the precipitation downdraft. This example of water vapour distribution and rain radar observation comparisons demonstrate the potential of co-localized rain radars with dense GPS networks. Such measurements of tropospheric water being still rare in meteorology, these simultaneous, co-localized and high resolution observations of two phases of water is an exceptional opportunity to advance our understanding of convection processes at small scales. This approach should prove useful to improve the physical parameterization in numerical weather prediction models, particularly critical for the forecast of precipitation. 


\section{Conclusions}

In this paper, data from a two months campaign that took place in autumn 2002 in southeastern France (OHM-CV 2002) and involved 21 GPS receivers forming a dense network over a 30 by $30 \mathrm{~km}$ domain have been presented and analysed along two paths. First, we conducted a sensitivity study of GPS tropospheric parameters ZTD and horizontal gradients estimated from our dense network. Once the parameter uncertainties related to our analysis strategy were well established, we inverted the GPS tropospheric observations in a tomographic approach to establish 3-D water vapour density fields above the network. Furthermore, we made use of the GPS network within the field-of-view of the Météo-France rain radar in Bollène to compare the GPS water vapour fields with the radar reflectivity fields related to precipitations, in order to highlight detailed features of the water vapour distribution in rainy situations.

Our sensitivity tests aimed at quantifying tropospheric parameter uncertainties related to network geometry, reference frame establishment, constraints on tropospheric parameter variability and un-modelled troposphere quantified in one way phase residuals. The test of the influence of the network geometry (see Appendix for details) yielded a $1 \mathrm{~mm}$ bias with $3 \mathrm{~mm}$ std for ZTD in average over all tested configurations (maximum values of $20 \mathrm{~mm}$ bias, and $4 \mathrm{~mm}$ std). Gradients differ most for stations at the edge of the network (a maximum $50 \mathrm{~mm}$ bias with a $20 \mathrm{~mm} \mathrm{std}$ ). On average, we found a $1 \mathrm{~mm}$ bias with $9 \mathrm{~mm}$ std for the EW component and a $2 \mathrm{~mm}$ bias with $12 \mathrm{~mm}$ std for the NS component.

We have also tested the sensitivity of ZTD and gradients to the choice of the reference frame. The difference of ZTD between a reference frame constrained to ITRF and a free solution is about $4 \mathrm{~mm}$ (higher in ITRF). There is no correlation or anti-correlation of ZTD with the vertical position when no constraints are applied to the station coordinates. Gradients are different by $1-3 \mathrm{~mm}$, except for stations constrained to their ITRF position $(7-8 \mathrm{~mm})$. Comparisons with radiosondes over a 21-d period indicate that the free solution is closer to the radiosoundings than the ITRF solution (bias decreases from 5.4 to $1.7 \mathrm{~mm}$ ).

We examined the effect of constraining the time variability of the GPS tropospheric measurements. For our parameter estimation, we have chosen constraints of $0.02 \mathrm{~m} \mathrm{~h}^{-1 / 2}$ for ZTD and GRAD variability, reproducing most but not all of the information of the most relaxed evaluation, without creating jumps at session boundaries. There is relative small mean biases between all the solution shown Fig. 6 and 7 ( $3 \mathrm{~mm}$ for ZTD, $9 \mathrm{~mm}$ for EW GRAD and $10 \mathrm{~mm}$ for NS GRAD) but larger std (4 mm for ZTD, $14 \mathrm{~mm}$ for EW GRAD and $16 \mathrm{~mm}$ for NS GRAD).

Finally, we have shown that one way post-fit phase residuals could consist to a large part of a tropospheric signal of higher order than ZTD and gradients. Including these high resolution observations (available for every station-satellite pair every $30 \mathrm{~s}$ ) could therefore increase the information of the anisotropic troposphere. However, persistent patterns due to local signal multi-path should be carefully filtered out first. In any case, the contribution of an observed maximum residual of $20 \mathrm{~mm}$ at zenith is small compared to ZTD and GRAD ( $5 \%$ of ZTD while gradients contribute with $12 \%$ to ZTD).

In conclusion, we found that a good compromise for an efficient operational analysis is to use sub-networks of 24 stations including 10 widely spread reference stations and with a cluster of 8 local stations and 4 permanent stations in intermediate, regional distances, to minimise calculation time (20 min for a GAMIT solution on a Linux PC). The reference frame should be free, and ZTD and gradients moderately constrained $\left(0.02 \mathrm{~m} \mathrm{~h}^{-1 / 2}\right)$. After filtering of multi-path interferences, phase residuals could be interpreted as higher order tropospheric signal. The cumulated effect of network geometry, reference frame choice and tropospheric parameter constraints evaluates ZTD bias and std to better than $8 \mathrm{~mm}$ and $7 \mathrm{~mm}$, the GRAD EW bias and std to better than $12 \mathrm{~mm}$ and $35 \mathrm{~mm}$ and the GRAD NS bias and std to better than $14 \mathrm{~mm}$ and $40 \mathrm{~mm}$. Phase residuals should average out over one calculation session and only contribute to std. Our solution therefore produces PWV reaching the uncertainties of classical meteorological measurements, i.e. about $1 \mathrm{~mm}$ PWV which corresponds to $6.18 \mathrm{~mm}$ ZTD.

In the second part of our work, we have presented a tomographic inversion scheme of SWD measurements estimated in direction of the satellites visible from the network. If we consider maximum errors of 15-20\% SWD as quantified by our methodological work (adding biases and standard deviations for ZTD and GRAD), we can evaluate uncertainties in the order of $1.5-2.0 \mathrm{~g} \mathrm{~m}^{-3}$ for average densities of $10 \mathrm{~g} \mathrm{~m}^{-3}$ in the $500 \mathrm{~m}$ altitude cross section. However, constraining the tomographic inversion to fit the more precise PWV measurements at the station locations should decrease this error, joining the results of sensitivity tests made with the TSAAR software (Reverdy, 2008). These tests indicated about $1 \mathrm{~g} \mathrm{~m}^{-3}$ as typical uncertainty for water vapour density measured above the OHM-CV network, taking into account the real OHMCV network geometry and altitude distribution.

The spatial resolution of the tomographic inversion corresponds to the mean station spacing in the horizontal direction $(5 \mathrm{~km})$ and $500 \mathrm{~m}$ in the vertical direction for atmospheric layers close to the ground. Resolution is decreasing toward higher altitude. Concerning time resolution, the successive water vapour maps every $15 \mathrm{~min}$ show already significantly evolving distributions, underlining the high sensitivity of GPS measurements to rapid water vapour fluctuations.

The comparison of the tomographic results with the PWV field indicates improved horizontal resolution by the exploitation of slant observations with tomography as the water vapour distribution is constrained in-between neighbouring sites. With regard to two dimensional PWV fields, tomographic inversion permits to take advantage of both the height differences of the stations and the slant observations 
to constrain the vertical distribution of water vapour. The observation of vertical water vapour variations is very limited, but is very relevant information for meteorological analyses. In our case study, the water vapour tomography for the rain event in the evening of 21 October 2002 resolved an anomaly of water vapour density close to the ground in the NW part of the network, starting in a NNW-SSE oriented valley before spreading out over a larger zone.

The GPS network was conceived to be situated in the field of view of the Bollène weather rain radar. We had therefore the opportunity to compare the tomographic results with independent, co-localized and synchronous measurements of rain. The confrontation of the water vapour density field with the rain field relates the depletion of tropospheric humidity in the NW of the network at the passage of a precipitation zone. Possible mechanisms for the decrease in water vapour density observed could be condensation, accretion, or downdraft associated with convective processes. This example shows that the dense OHM-CV GPS network could produce significant, high resolution observations of water vapour variability, on both at spatial $(5 \mathrm{~km})$ and temporal scales $(15 \mathrm{~min})$.

GPS tomography proves to be a potentially useful tool to investigate the water vapour distribution related to convective rainfall events. More generally, it can provide a significant contribution to the analysis of small scale water vapour dynamics. This finally might result in better parameterisation of water vapour in numerical weather prediction models, improving their capacities for precipitation forecast.

As a consequence of the successful use of GPS water vapour observations for hydro-meteorological studies in the framework of OHM-CV, the regional temporary stations are nowadays converted into permanent sites and take part in large hydro-meteorological projects such as the ongoing HyMeX project (Hydrological cycle in the Mediterranean Experiment, http://www.hymex.org). This international project running from 2010 to 2020 aims at a better understanding and quantification of the hydrological cycle and related processes in the Mediterranean, with emphasis on high-impact weather events, inter-annual to decadal variability of the Mediterranean coupled system, and associated trends in the context of global change. The permanent GPS stations installed between 2003 and 2007 in the OHM-CV study area will continue providing significant data for improving our understanding of the tropospheric water cycle.

Acknowledgements. We would like to thank all collaborators contributing to the project with their expertise (J.-P. Glot, S. Anquetin, O. Bock, P. Tabary), and the public and private persons permitting the installation of a GPS station on their ground over the two months time span. The PhD thesis grant of $\mathrm{H}$. Brenot and the measurement campaign were sponsored by the French research programme ACI CatNat, the PATOM and PNRH research programs of the CNRS-INSU (the National French Institute of Universe Sciences). The PhD thesis of M. Reverdy was a French ministerial grant.
Edited by: V. Amiridis

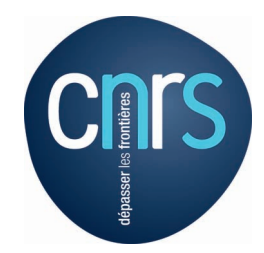

The publication of this article is financed by CNRS-INSU.

\section{References}

Adams, D. K., Gutman, S. I., Holub, K. L., and Pereira, D. S.: GNSS Observations of Deep Convective Time scales in the Amazon, Geophys. Res. Lett., 40, 2818-2823, doi:10.1002/grl.50573, 2013.

Altamimi, Z., Sillard, P., and Boucher, C.: ITRF 2000 : A New Release of the International Terrestrial Reference Frame for Earth Science Applications, J. Geophys. Res., B10, 2214, 1-19, doi:10.1029/2001JB000561, 2002.

Askne, J. and Nordius, H.: Estimation of Tropospheric Delay for Microwaves from Surface Weather Data, Radio Science, 22, 379-386, doi:10.1029/RS022i003p00379, 1987.

Bastin, S., Champollion, C., Bock, O., Drobinski, P., and Masson, F.: On the use of GPS tomography to investigate water vapor variability during a Mistral/sea breeze event in southeastern France, Geophys. Res. Lett., 32, L05808, doi:10.1029/2004GL021907, 2005.

Behrend D., Haas, R., Pino, D., Gradinarsky, L. P., Keihm, S. J., Schwarz, W., Cucurull, L., and Rius, A.: mm5 derived ZWDs compared to observational results from VLBI, GPS and WVR, Physics and Chemistry of the Earth, Parts A/B/C, 27, 301-308, doi:10.1016/S1474-7065(02)00004-9, 2002.

Benjamin, S. G., Jamison, B. D., Moninger, W. R., Sahm, S. R., Schwartz, B. E., and Schlatter, T. W.: Relative Short-Range Forecast Impact from Aircraft, Profiler, Radiosonde, VAD, GPS-PW, METAR, and Mesonet Observations via the RUC Hourly Assimilation Cycle, Mon. Weather Rev., 138, 13191343, doi:10.1175/2009MWR3097.1, 2010.

Bennitt, G. V. and Jupp, A.: Operational Assimilation of GPS Zenith Total Delay Observations into the Met Office Numerical Weather Prediction Models, Mon. Weather Rev., 140, 27062719, doi:10.1175/MWR-D-11-00156.1, 2012.

Bevis, M., Businger, S., Herring, T. A., Rocken, C., Anthes, R. A., and Ware, R. H.: GPS Meteorology: Remote Sensing of Atmospheric Water Vapor Using the Global Positioning System, J. Geophys. Res., 97, 15787-15801, doi:10.1029/92JD01517, 1992.

Bevis, M., Businger, S., Chiswell, S., Herring, T., Anthes, R., Rocken, C., and Ware, R.: GPS Meteorology: Mapping Zenith Wet Delays onto Precipitable Water, J. Appl. Meteorol., 33, 379-386, doi:10.1175/15200450(1994)033<0379:GMMZWD>2.0.CO;2, 1994.

Bock, O. and Doerflinger, E.: Atmospheric modeling in GPS data analysis for high accuracy positioning, Phys. Chem. Earth, Part A: Solid Earth and Geodesy, 26, 373-383, doi:10.1016/S14641895(01)00069-2, 2001 
Bock, O., Doerflinger, E., Masson, F., Walpersdorf, A., Van Baelen, J., Tarniewicz, J., Troller, M., Somieski, A., Geiger, A., and Buerki, B.: GPS Water Vapor Tomography : Description and First Results of the ESCOMPTE field Experiment, Phys. Chem. Earth, 29, 149-157, doi:10.1016/j.atmosres.2004.04.003, 2004.

Bock, O., Bouin, M.-N., Walpersdorf, A., Lafore, J.-P., Janicot, S., and Guichard, F.: Assessment of GPS data over Africa: Analysis of precipitable water vapour, Q. J. Roy. Meteorol. Soc., 133, 2001-2027, doi:10.1002/qj.185, 2007.

Boehm, J., Niell, A., Tregoning, P., and Schuh, H.: Global Mapping Function (GMF): A new empirical mapping function based on numerical weather model data, Geophys. Res. Lett., 33, L07304, doi:10.1029/2005GL025546, 2006a.

Boehm, J., Werl, B., and Schuh, H.: Troposphere mapping functions for GPS and very long baseline interferometry from European Centre for Medium-Range Weather Forecasts operational analysis data, J. Geophys. Res., 111, B02406, doi:10.1029/2005JB003629, 2006b.

Braun, J., Rocken, C., and Ware, R.: Validation of Line-of-Sight Water Vapor Measurements with GPS, Radio Science, 36, 459472, doi:10.1029/2000RS002353, 2001.

Brenot, H. and Warnant, R.: Characterization of the tropospheric small-scale activity, Technical Report ESA, WP250, GALOCAD project, 2008

Brenot, H., Ducrocq, V., Walpersdorf, A., Champollion, C., and Caumont, O.: GPS zenith delay sensitivity evaluated from high resolution NWP simulations of the 8-9th September 2002 flashflood over southeastern France, J. Geophys. Res., 111, D15105, doi:10.1029/2004JD005726, 2006.

Brenot, H., Neméghaire, J., Delobbe, L., Clerbaux, N., De Meutter, P., Deckmyn, A., Delcloo, A., Frappez, L., and Van Roozendael, M.: Preliminary signs of the initiation of deep convection by GNSS, Atmos. Chem. Phys., 13, 5425-5449, doi:10.5194/acp13-5425-2013, 2013

Bresson, É., Ducrocq, V., Nuissier, O., Ricard, D., and de Saint-Aubin, C.: Idealized numerical simulations of quasistationary convective systems over the Northwestern Mediterranean complex terrain, Q. J. R. Meteorol. Soc., 138, 1751-1763, doi:10.1002/qj.1911, 2012.

Businger, S., Chiswell, S., Bevis, M., Duan, J., Anthes, R., Rocken, C., Ware, R., Van Hove, T., and Solheim, F.: The Promise of GPS in Atmospheric Monitoring, Bull. Amer. Meteorol. Soc., 77, 379-386, doi:10.1175/15200477(1996)077<0005:TPOGIA>2.0.CO;2, 1996.

Ceresetti, D.: Structure spatio-temporelle des fortes précipitations: application à la région Cévennes-Vivarais, $\mathrm{PhD}$ in French and English, LTHE, Grenoble, France, 2011.

Champollion, C., Masson, F., Van Baelen, J., Walpersdorf, A., Chéry, J., and Doerflinger, E.: GPS monitoring of the tropospheric water vapour distribution and variation during the September 9, 2002, torrential precipitation episode in the Cévennes (Southern France), J. Geophys. Res. Atmos., 109, D24102, doi:10.1029/2004JD004897, 2004.

Champollion, C., Masson, F., Bouin, M.-N., Walpersdorf, A., Doerflinger, E., Bock, O., and Van Baelen, J.: GPS water vapour tomography: preliminary results from the ESCOMPTE field experiment, Atmos. Res., 74, 253-274, doi:10.1016/j.atmosres.2004.04.003, 2005.
Chen, G. and Herring, T. A.: Effects of atmospheric azimuthal asymmetry on the analysis of space geodetic data, J. Geophys. Res., 102, 20489-20502, doi:10.1029/97JB01739, 1997.

Davis, J. L., Herring, T. A., Shapiro, I. I., Rogers, A. E. E., and Elgered, G.: Geodesy by Interferometry : Effects of Atmospheric Modeling Errors on Estimates of Baseline Length, Radio Science, 20, 1593-1607, doi:10.1029/RS020i006p01593, 1985.

Delrieu, G., Nicol, J., Yates, E., Kirstetter, P.-E., Creutin, J.-D., Anquetin, S., Obled, C., Saulnier, G.-M., Ducrocq, V., Gaume, E., Payrastre, O., Andrieu, H., Ayral, P.-A., Bouvier, C., Neppel, L., Livet, M., Lang, M., Parent du-Châtelet, J., Walpersdorf, A., and Wobrock, W.: The Catastrophic Flash-Flood Event of 8-9 September 2002 in the Gard Region, France : a First Case Study for the Cévennes-Vivarais Mediterranean Hydrometeorological Observatory, J. Hydrometeorol., 6, 34-51, doi:10.1175/JHM400.1, 2005.

Duan, J., Bevis, M., Fang, P., Bock, Y., Chiswell, S., Businger, S., Rocken, C., Solheim, F., van Hove, T., Ware, R., McClusky, S., Herring, T. A., and King, R. W.: GPS Meteorology: Direct Estimation of the Absolute Value of Precipitable Water, J. Appl. Meteor., 35, 830-838, doi:10.1175/15200450(1999)038<0941:ACOPWV>2.0.CO;2, 1996.

Ducrocq, V., Ricard, D., Lafore, J. P., and Orain, F.: Storm-Scale Numerical Rainfall Prediction for Five Precipitations Events over France : on the Importance of the Initial Humidity Field, Weather Forecast., 17, 1236-1256, 2002.

Elgered, G.: An Overview of COST 716 : Exploitation of GroundBased GPS Climate and Numerical Weather Prediction Applications, Phys. Chem. Earth, 26, 399-404, 2001.

Elgered, G., Davis, J. L., Herring, T. A., and Shapiro, I. I.: Geodesy by Radio Interferometry : Water Vapour Radiometry for Estimation of the Wet Delay, J. Geophys. Res., 96, 6541-6555, doi:10.1029/90JB00834, 1991.

Emardson, T. and Derks, H.: On the Relation Between the Wet Delay and the Integrated Precipitable Water Vapour in the European Atmosphere, Meteorol. Appl., 6, 1-12, doi:10.1175/15200450(2003)042<1547:AAVOGT>2.0.CO;2, 1999.

Flores, A., Ruffini, G., and Rius, A.: 4D tropospheric tomography using GPS slant wet delays, Ann. Geophys., 18, 223-234, doi:10.1007/s00585-000-0223-7, 2000.

Gendt, G., Dick, G., Reigber, C., Tomassini, M., Liu, Y., and Ramatschi, M.: Near real time GPS water vapour monitoring for numerical weather prediction in Germany, J. Meteorol. Soc. Jpn., 82, 361-370, 2004

Gradinarsky, L. P.: Sensing Atmospheric Water Vapor Using Radio Waves, Ph.D. thesis, School of Electrical Engineering, Chalmers University of Technology, Göteborg, Sweden, 2002.

Gradinarsky, L. P. and Jarlemark, P.: Ground-Based GPS Tomography of Water Vapor: Analysis of Simulated and Real Data, J. Meteorol. Soc. Jpn., 82, 551-560, 2004.

Guerova, G., Bettems, J.-M., Brockmann, E., and Matzler, C.: Assimilation of COST 716 Near-real Time GPS data in the nonhydrostatic limited area model used at MeteoSwiss, Meteorol. Atmos. Phys., 91, 149-164, doi:10.1007/s00703-005-01106, 2006

Gutman, S. I., Sahm, S. R., Benjamin, S. G., Schwarz, B. E., Holub, K. L., Stewart, J. Q., and Smith, T. L.: Rapid retrieval and assimilation of ground based GPS precipitable water observations 
at the NOAA Forecast Systems Laboratory: impact on weather forecasts, J. Meteorol. Soc. Jpn., 82, 351-360, 2004.

Haan, S., Jones, J., and Vedel, H.: EUMETNET GPS Water Vapour (E-GVAP), Presentation at European Meteorological Society, Ljubljana, Slovenia, 2006.

Haase, J., Calais, E., Talaya, J., Rius, A., Vespe, F., Santangelo, R., Huang, X.-Y., Davila, J. M., Ge, M., Cucurull, L., Flores, A., Sciarretta, C., Pacione, R., Boccolari, M., Pugnaghi, S., Vedel, H., Mogensen, K., Yang, X., and Garate, J.: The Contributions of the MAGIC Project to the COST 716 Objectives of Assessing the Operational Potential of Ground-Based GPS Meteorology on an International Scale, Phys. Chem. Earth, 26, 433-437, doi:10.1016/S1464-1895(01)00079-5, 2001.

Haase, J., Ge, M., Vedel, H., and Calais, E.: Accuracy and Variability of GPS Tropospheric Delay Measurements of Water Vapor in the Western Mediterranean, J. Appl. Meteor., 42, 1547-1568, doi:10.1175/1520-0450(2003)042<1547:AAVOGT>2.0.CO;2, 2003.

Herring, T. A., King, R. W., and McClusky, S. C.: Introduction to GAMIT/GLOBK, Release 10.3, Dep. of Earth Atmos. and Planet. Sci., Mass. Inst. of Technol., Cambridge, Mass., 2006.

Ineichen, D., Gurtner, W., Springer, T., Engelhardt, G., Luthardt, J., and Ihde, J.: EUVN 97 Combined GPS Solution, in EUREF Publication no.7/II, Mitteilungen des Bundesamts für Kartographie und Geodäsie, Band 7, Frankfurt a. M., 1999.

Kämpfer, N.: Monitoring Atmospheric Water Vapour, ISSI Scientific Report Series, 10, 326 pp., doi:10.1007/978-1-4614-39097_9, 2012.

Labbouz, L., Van Baelen, J., Tridon, F., Reverdy, M., Hagen, M., Bender, M., Dick, G., Gorgas, T., and Planche, C.: Precipitation on the lee side of the Vosges Mountains: Multi-instrumental study of one case from the COPS campaign, Meteorologische Z., 4, 413-432, 2013.

Macpherson, S. R., Deblonde, G., Aparicio, J. M., and Casati, B.: Impact of NOAA Ground-Based GPS Observations on the Canadian Regional Analysis and Forecast System, Mon. Weather Rev., 136, 2727-2746, 2008.

Nakamura, H., Koizumi, K., and Mannoji, N.: Data assimilation of GPS precipitable water vapor into the JMA mesoscale numerical weather prediction model and its impact on rainfall forecasts, J. Meteorol. Soc. Jpn., 82, 441-452, 2004.

Niell, A. E.: Global mapping functions for the atmosphere delay at radio wavelengths, J. Geophys. Res., 101, 3227-3246, doi:10.1029/95JB03048, 1996.

Niell, A. E.: Improved atmospheric mapping functions for VLBI and GPS, Earth Planet. Space, 52, 699-702, 2000.

Pacione, R., Fionda, E., Ferrara, R., Lanotte, R., Sciarretta, C., and Vespe, F.: Comparison of atmospheric parameters derived from GPS, VLBI and a ground-based microwave radiometer in Italy, PCE, 27, 309-316, doi:10.1016/S1474-7065(02)00005-0, 2002.

Perler, D., Geiger, A., and Hurter, F.: 4D GPS water vapor tomography: new parameterized approaches, J. Geod., 85, 539-550, doi:10.1007/s00190-011-0454-2, 2011.

Poli, P., Moll, P., Rabier, F., Desroziers, G., Chapnik, B., Berre, L., Healy, S. B., Andersson, E., and El Guelai, F.-Z.: Forecast impact studies of zenith total delay data from European near real-time GPS stations in Météo France 4DVAR, J. Geophys. Res., 112, D06114, doi:10.1029/2006JD007430, 2007.
Reverdy, M.: Estimation des paramètres atmosphériques par GPS: analyse de la variabilité spatio-temporelle de la vapeur d'eau, $\mathrm{PhD}$ thesis in French, University Clermont-Ferrand, 2008.

Rocken, C., Hove, T. V., Johnson, J., Solheim, F., and Ware, R.: GPS/STORM : GPS Sensing of Atmospheric Water Vapor for Meteorology, J. Atmos. Ocean. Tech., 12, 2631-2634, doi:10.1175/1520-0426(1995)012<0468:GSOAWV>2.0.CO;2, 1995.

Saastamoinen, J.: Atmospheric Correction for the Troposphere and Stratosphere in Radio ranging of satellites, Geophys. Monogr. Ser., 15, 247-251, doi:10.1029/GM015p0247, 1972.

Sandwell, D. T.: Biharmonic spline interpolation of GEOS-3 and SEASAT altimeter data, Geophys. Res. Lett., 14, 139-142, doi:10.1029/GL014i002p00139, 1987

Santerre, R.: Impact of GPS satellite sky distribution, Manuscriptae Geodaetica, 16, 28-53, 1991.

Schneider, M., Romero, P. M., Hase, F., Blumenstock, T., Cuevas, E., and Ramos, R.: Continuous quality assessment of atmospheric water vapour measurement techniques: FTIR, Cimel, MFRSR, GPS, and Vaisala RS92, Atmos. Meas. Tech., 3, 323338, doi:10.5194/amt-3-323-2010, 2010.

Sguerso, D., Labbouz, L., and Walpersdorf, A.: 14 years of GPS tropospheric delays in the French-Italian border region: A data base for meteorological and climatological analyses, International Workshop "The Role of Geomatics in Hydrogeological Risk", Padua, 26-28 February 2013.

Smith, T. L., Benjamin, S. G., Gutman, S. I., and Sahm, S.: ShortRange Forecast Impact from Assimilation of GPS-IPW Observations into the Rapid Update Cycle, Mon. Weather Rev., 135, 2914-2930, doi:10.1175/MWR3436.1, 2007.

Tregoning, P., Boers, R., O’Brien, D., and Hendy, M.: Accuracy of Absolute Precipitable Water Vapor Estimates from GPS Observations, J. Geophys. Res., 103, 28701-28710, doi:10.1029/98JD02516, 1998.

Troller M., Geiger A., Brockmann E., Bettems J.-M., Burki B., and Kahle H.-G.: Tomographic determination of the spatial distribution of water vapour using GPS observations, Adv. Space Res., 37, 2211-2217, doi:10.1016/j.asr.2005.07.002, 2006.

Van Baelen, J. and Penide, G.: Study of water vapor vertical variability and possible cloud formation with a small network of GPS stations, Geophys. Res. Lett., 36, L02804, doi:10.1029/2008GL036148, 2009.

Van Baelen, J., Aubagnac, J.-P., and Dabas, A.: Comparison of Near Real Time Estimates of Integrated Water Vapor Derived with GPS, Radiosondes, and Microwave Radiometer, J. Atmos. Ocean. Technol., 22, p. 201, doi:10.1175/JTECH-1697.1, 2005.

Van Baelen, J., Reverdy, M., Tridon, F., Labbouz, L., Dick, G., Bender, M., and Hagen, M.: On the relationship between water vapour field evolution and precipitation systems lifecycle, Q. J. R. Meteorol. Soc., 137, 204-223, doi:10.1002/qj.785, 2011.

Van der Marel, H.: COST-716 Demonstration Project for the Near Real-Time Estimation of Integrated Water Vapour from GPS, Phys. Chem. Earth, 29, 187-199, 2004.

Vedel, H., Mogensen, K., and Huang, X.-Y.: Calculation of Zenith Delays From Meteorological Data Comparison of NWP Model, Radiosonde and GPS Delays, Phys. Chem. Earth, 26, 497-502, doi:10.1016/S1464-1895(01)00091-6, 2001.

Walpersdorf, A., Calais, E., Haase, J., Eymard, L., Desbois, M., and Vedel, H.: Atmospheric Gradients Estimated by GPS Compared 
to a High Resolution Numerical Weather Prediction (NWP) Model, Phys. Chem. Earth, 26, 147-152, doi:10.1016/S14641895(01)00038-2, 2001.

Walpersdorf, A., Bock, O., Doerflinger, E., Masson, F., Van Baelen, J., Somieski, A., and Buerki, B.: Data analysis of a dense GPS network operated during the ESCOMPTE campaign: First results, Phys. Chem. Earth, 29, 201-211, doi:10.1016/j.pce.2004.01.002, 2004.

Walpersdorf, A., Bouin, M.-N., Bock, O., and Doerflinger, E.: Assessment of GPS data for meteorological applications over Africa: Study of error sources and analysis of positioning accuracy, J. Atmos. Sol. Terr. Phys., 69, 1312-1330, doi:10.1016/j.jastp.2007.04.008, 2007.
Wang, J., Zhang, L., Dai, A., Van Hove, T., and Van Baelen, J.: A near-global 2-hourly data set of atmospheric precipitable water from ground-based GPS measurements, J. Geophys. Res., 112, D11107, doi:10.1029/2006JD007529, 2007.

Yan, X., Ducrocq, V., Poli, P., Hakam, M., Jaubert, G., and Walpersdorf, A.: Impact of GPS zenith delay assimilation on convective scale prediction of Mediterranean heavy rainfall, J. Geophys. Res., 114, D03104, doi:10.1029/2008JD011036, 2009.

Yang, X., Sass, B. H., Elgered, G., Johansson, J. M., and Emardson, T. R.: A Comparison of Precipitable Water Vapor Estimates by an NWP Simulation and GPS Observations, J. Appl. Meteor., 38, 941-956, doi:10.1175/1520-0450(1999)038, 1999. 


\section{Appendix A}

\section{Mathematical background}

Table A1 presents biases and standard deviations for ZTD and GRAD estimations in different sub-networks with respect to a reference solution over a maximum number of 44 GPS stations. All solutions include the same 10 widely spread reference stations (example in Fig. 3f). We also try to consider in all solutions the same 5 local test sites shown in Fig. 3 (Fig. 3a, b, c and d: 4 temporary stations of the OHM-CV network; Fig. 3e: 1 permanent station close to the OHM-CV network). The number of stations per solution varies from 15 to 38 . The geometries tested include:

a. small networks (10 reference stations +6 temporary stations +4 local permanent stations), 3 calculations of small networks are required to assess measurements of the 18 temporary stations of our dense network and the 11 regional and permanent stations close to this area (see Fig. 1);

b. regular sub-sampling of the network (10 ref. stations +4 temporary stations +9 local permanent stations), 3 different networks are tested;

c. clustering of local sites (10 ref. stations +4 temporary stations + 5-6 local permanent stations), 3 different geographical distributions are tested (east, centre and west of the network);

d. increasing network (10 ref. stations +5 test stations $+0-20$ local stations) considering the same base network and adding step by step 3, 6, 9, 12, 15 and 20 stations. Only the solutions with $6,9,12$ and 20 additional stations are shown Table 5.
Other different geographical distributions of the network have also been tested (a total of 36 configurations). About 230000 ZTD and gradients (EW GRAD and NW GRAD components) evaluations have been considered for the 3 days of our statistical study. The worst geographical distribution shown in Table 5 (indicated as "Worst config.") corresponds to a network of 18 stations ( 10 ref. stations +4 temporary stations +4 permanent stations located to the south-west of the dense network at more than $500 \mathrm{~km}$ ). This heterogeneous geographical distribution shows a maximal ZTD bias of $-26.5 \mathrm{~mm}$, an EW GRAD bias of $76.1 \mathrm{~mm}$, and a NS GRAD bias of $93.8 \mathrm{~mm}$. The tropospheric parameters seem to be badly estimated for isolated stations at the limit of the network, what is the case for most of the stations in this network configuration. We show also average results for the 36 different configurations of networks considered in Table 5. Here, the Max bias indicated corresponds to 4 configurations with again respectively 18 stations for which the isolated geographical distribution of stations prohibits correct tropospheric parameter estimation. To avoid such miss-estimates a relative uniform geographical distribution has to be considered. Considering all configurations, we found an average error on ZTD of about $5 \mathrm{~mm}$ (bias of $0.9 \mathrm{~mm}$ and std of $3.4 \mathrm{~mm}$ ), and of about $20 \mathrm{~mm}$ on EW and NS GRAD (bias of $0.6 \mathrm{~mm}$ and std of $22.2 \mathrm{~mm}$, and bias of $-2.6 \mathrm{~mm}$ and std of $23.7 \mathrm{~mm}$, respectively). 
Table A1. Bias $(\Delta)$ and standard deviation $(\delta)$ of ZTD and GRAD evaluations (EW and NS components) of sub-networks with respect to the reference network. Statistical results are shown for 10 widely spread reference stations, the permanent stations, the temporary stations of our dense network, and for all the stations. The number of ZTD and GRAD evaluations entering in the statistics are indicated, and maximum biases over all tests are shown in the last two lines.

\begin{tabular}{|c|c|c|c|c|c|c|}
\hline Networks & GPS sites & $\begin{array}{l}\text { ZTD } \\
\Delta[\mathrm{mm}] \delta[\mathrm{mm}]\end{array}$ & \# ZTD & $\begin{array}{l}\text { EW GRAD } \\
\Delta[\mathrm{mm}] \delta[\mathrm{mm}]\end{array}$ & $\begin{array}{l}\text { NS GRAD } \\
\Delta[\mathrm{mm}] \delta[\mathrm{mm}]\end{array}$ & \# GRAD \\
\hline (a) Small & Reference (10) & $-1.1 \pm 3.8$ & 8478 & $2.5 \pm 23.4$ & $-4.9 \pm 25.3$ & 4257 \\
\hline 10 ref. sites & Permanent (4) & $-0.1 \pm 3.0$ & 3468 & $-0.4 \pm 22.0$ & $-1.0 \pm 24.0$ & 1740 \\
\hline+6 tempo. sites & Temporary (6) & $-1.0 \pm 3.9$ & 5202 & $1.1 \pm 26.8$ & $-6.6 \pm 30.9$ & 2610 \\
\hline+4 local sites & All (20) & $-1.0 \pm 3.8$ & 17148 & $1.9 \pm 24.3$ & $-.5 .1 \pm 26.9$ & 8607 \\
\hline (b) Sub-sampling & Reference (10) & $-1.5 \pm 3.6$ & 8478 & $-0.7 \pm 23.3$ & $-2.4 \pm 24.9$ & 4257 \\
\hline 10 ref. sites & Permanent (9) & $-1.5 \pm 3.4$ & 7803 & $-0.0 \pm 25.2$ & $1.8 \pm 26.7$ & 3915 \\
\hline \multirow[t]{2}{*}{+13 local sites } & Temporary (4) & $-1.4 \pm 3.8$ & 3468 & $-1.0 \pm 27.1$ & $-3.6 \pm 29.6$ & 1740 \\
\hline & All (23) & $-1.5 \pm 3.6$ & 19749 & $-0.5 \pm 24.8$ & $-0.9 \pm 26.6$ & 9912 \\
\hline (c) Clustering & Reference (10) & $-1.2 \pm 3.8$ & 8478 & $0.5 \pm 23.1$ & $-3.7 \pm 25.1$ & 4257 \\
\hline 10 ref. sites & Permanent (5-6) & $-0.9 \pm 3.5$ & 4624 & $-0.3 \pm 24.1$ & $-0.0 \pm 24.9$ & 2320 \\
\hline$+9-10$ local & Temporary (4) & $-1.3 \pm 3.7$ & 3468 & $-2.4 \pm 26.8$ & $-6.0 \pm 30.4$ & 1740 \\
\hline sites & All $(19-20)$ & $-1.2 \pm 3.7$ & 16570 & $-0.3 \pm 24.2$ & $-3.2 \pm 26.3$ & 8317 \\
\hline (d) Increasing & Reference (10) & $-1.3 \pm 3.7$ & 2826 & $1.8 \pm 26.7$ & $-5.1 \pm 25.0$ & 1419 \\
\hline 10 ref. sites & Permanent (1) & $-0.5 \pm 2.5$ & 289 & $-2.4 \pm 24.9$ & $-2.8 \pm 20.0$ & 145 \\
\hline \multirow[t]{2}{*}{+5 test sites } & Temporary (4) & $-1.5 \pm 3.8$ & 1156 & $-3.6 \pm 29.6$ & $-7.1 \pm 31.4$ & 580 \\
\hline & All (15) & $-1.3 \pm 3.7$ & 4271 & $-0.9 \pm 26.6$ & $-5.5 \pm 26.6$ & 2144 \\
\hline \multirow[t]{4}{*}{+6 sites } & Reference (10) & $-0.7 \pm 3.7$ & 2826 & $-0.7 \pm 23.5$ & $-1.4 \pm 25.4$ & 1419 \\
\hline & Permanent (5) & $-0.7 \pm 3.0$ & 1445 & $-0.7 \pm 24.8$ & $2.4 \pm 25.9$ & 725 \\
\hline & Temporary (6) & $-0.6 \pm 3.0$ & 1734 & $-0.8 \pm 24.9$ & $-2.4 \pm 27.6$ & 870 \\
\hline & All (21) & $-0.7 \pm 3.5$ & 6005 & $-0.7 \pm 24.4$ & $-0.6 \pm 26.5$ & 3014 \\
\hline \multirow[t]{4}{*}{+9 sites } & Reference (10) & $-0.4 \pm 2.8$ & 2826 & $5.6 \pm 14.8$ & $-4.5 \pm 14.5$ & 1419 \\
\hline & Permanent (6) & $-0.6 \pm 2.7$ & 1734 & $2.4 \pm 15.6$ & $-4.0 \pm 16.9$ & 870 \\
\hline & Temporary (8) & $-0.5 \pm 2.5$ & 2312 & $3.7 \pm 12.2$ & $-5.2 \pm 11.7$ & 1160 \\
\hline & All (24) & $-0.5 \pm 2.7$ & 6872 & $4.5 \pm 14.3$ & $-4.6 \pm 14.2$ & 3449 \\
\hline \multirow[t]{4}{*}{+12 sites } & Reference (10) & $-0.4 \pm 2.7$ & 2826 & $4.6 \pm 12.5$ & $-3.2 \pm 12.8$ & 1419 \\
\hline & Permanent (7) & $-0.4 \pm 3.0$ & 2023 & $2.6 \pm 10.3$ & $-2.4 \pm 10.3$ & 1015 \\
\hline & Temporary (10) & $-0.2 \pm 2.6$ & 2890 & $3.0 \pm 8.2$ & $-2.7 \pm 9.1$ & 1450 \\
\hline & All (27) & $-0.3 \pm 2.7$ & 7739 & $3.7 \pm 10.9$ & $-2.9 \pm 11.4$ & 3884 \\
\hline \multirow[t]{4}{*}{+20 sites } & Reference (10) & $-0.7 \pm 2.3$ & 2826 & $3.2 \pm 12.3$ & $-1.4 \pm 12.2$ & 1419 \\
\hline & Permanent (10) & $-0.6 \pm 2.4$ & 2890 & $1.6 \pm 12.2$ & $-0.5 \pm 12.8$ & 1450 \\
\hline & Temporary (15) & $-0.5 \pm 1.9$ & 4335 & $1.8 \pm 8.7$ & $-1.7 \pm 9.0$ & 2175 \\
\hline & All (35) & $-0.6 \pm 2.2$ & 10051 & $2.2 \pm 11.1$ & $-1.3 \pm 11.3$ & 5044 \\
\hline \multirow{6}{*}{$\begin{array}{l}\text { All the } 36 \text { configura- } \\
\text { tions } \\
\text { of networks }\end{array}$} & Reference (10) & Worst config. & Worst config. & Worst config. & Worst config. & Worst config. \\
\hline & Permanent (4) & $0.5 \pm 2.6$ & 2826 & $1.7 \pm 10.5$ & $-1.5 \pm 8.8$ & 1419 \\
\hline & Temporary (4) & $11.9 \pm 24.8$ & 1156 & $-0.2 \pm 21.7$ & $9.4 \pm 22.4$ & 580 \\
\hline & All (18) & $12.2 \pm 25.3$ & 1156 & $5.3 \pm 15.4$ & $15.0 \pm 33.8$ & 580 \\
\hline & & $7.1 \pm 19.8$ & 5138 & $2.2 \pm 15.9$ & $6.3 \pm 23.5$ & 2579 \\
\hline & & Max bias: -26.5 & 1 & Max bias: 76.1 & Max bias: 93.8 & 1 \\
\hline \multirow{6}{*}{$\begin{array}{l}10 \text { ref. Sites } \\
+5 \text { test sites } \\
+0-23 \text { sites }\end{array}$} & Reference (10) & Average & Average & Average & Average & Average \\
\hline & Permanent & $-1.0 \pm 3.7$ & 44606 & $1.7 \pm 21.5$ & $-3.6 \pm 24.0$ & 22841 \\
\hline & $(0-16)$ & $-0.9 \pm 3.4$ & 30008 & $0.2 \pm 22.0$ & $1.0 \pm 24.8$ & 13812 \\
\hline & Temporary & $-0.7 \pm 3.4$ & 41247 & $-0.2 \pm 17.7$ & $-3.5 \pm 22.4$ & 20845 \\
\hline & $(2-18)$ & $-0.9 \pm 3.4$ & 115861 & $0.6 \pm 20.2$ & $-2.6 \pm 23.7$ & 57498 \\
\hline & All (15-38) & Max bias: -26.5 & 1 & Max bias: 87.5 & Max bias: 116.7 & 1 \\
\hline
\end{tabular}

